OPEN ACCESS

Edited by:

Paul Donlin-Asp,

Max Planck Institute for Brain

Research, Germany

Reviewed by:

Angel Nunez,

Autonomous University of Madrid,

Spain

Adrian Rodriguez-Contreras,

The City College of New York (CUNY),

United States

*Correspondence:

Jimena Baleriola

jimena.baleriola@achucarro.org

${ }^{\dagger}$ These authors have contributed equally to this work and share first

authorship

Received: 31 March 2021

Accepted: 03 June 2021

Published: 29 June 2021

Citation:

Gamarra M, de la Cruz A Blanco-Urrejola M and Baleriola J (2021) Local Translation in Nervous System Pathologies.

Front. Integr. Neurosci. 15:689208. doi: 10.3389/fnint.2021.689208

\section{Local Translation in Nervous System Pathologies}

\author{
Maria Gamarra' ${ }^{1,2 t}$, Aida de la Cruz ${ }^{1,2+}$, Maite Blanco-Urrejola ${ }^{1,2,3}$ and \\ Jimena Baleriola ${ }^{1,3,4 *}$ \\ ${ }^{1}$ Laboratory of Local Translation in Neurons and Glia, Achucarro Basque Center for Neuroscience, Leioa, Spain, \\ ${ }^{2}$ Departamento de Neurociencias, Universidad del País Vasco (UPV/EHU), Leioa, Spain, ${ }^{3}$ Departamento de Biología Celular \\ e Histología, Universidad del País Vasco (UPV/EHU), Leioa, Spain, ${ }^{4}$ Ikerbasque, Basque Foundation for Science, Billbao, \\ Spain
}

Dendrites and axons can extend dozens to hundreds of centimeters away from the cell body so that a single neuron can sense and respond to thousands of stimuli. Thus, for an accurate function of dendrites and axons the neuronal proteome needs to be asymmetrically distributed within neurons. Protein asymmetry can be achieved by the transport of the protein itself or the transport of the mRNA that is then translated at target sites in neuronal processes. The latter transport mechanism implies local translation of localized mRNAs. The role of local translation in nervous system (NS) development and maintenance is well established, but recently there is growing evidence that this mechanism and its deregulation are also relevant in NS pathologies, including neurodegenerative diseases. For instance, upon pathological signals diseaserelated proteins can be locally synthesized in dendrites and axons. Locally synthesized proteins can exert their effects at or close to the site of translation, or they can be delivered to distal compartments like the nucleus and induce transcriptional responses that lead to neurodegeneration, nerve regeneration and other cell-wide responses. Relevant key players in the process of local protein synthesis are RNA binding proteins (RBPs), responsible for mRNA transport to neurites. Several neurological and neurodegenerative disorders, including amyotrophic lateral sclerosis or spinal motor atrophy, are characterized by mutations in genes encoding for RBPs and consequently mRNA localization and local translation are impaired. In other diseases changes in the local mRNA repertoire and altered local protein synthesis have been reported. In this review, we will discuss how deregulation of localized translation at different levels can contribute to the development and progression of nervous system pathologies.

Keywords: local translation, RNA localization, RNA binding proteins, mRNA transport, nervous system pathologies

\section{INTRODUCTION}

Neurons are morphologically the most complex cells in the nervous system (NS). They consist of a soma, from which several processes emerge. The characteristic asymmetric morphology of neurons allows them to create stable neural circuits. Through their dendrites and axons, neuronal processes are capable of receiving and integrating incoming signals from presynaptic terminals and 
transmitting them through signaling pathways to give response to diverse stimuli. The structural and functional asymmetry of neurons requires the asymmetrical distribution of the neuronal proteome, which is achieved by the transport of mature proteins or the transport of transcripts to target compartments in neuronal processes. In this article, we focus on the latter mechanism by which localized messenger RNAs (mRNAs) are transformed into proteins through a process known as local translation or local protein synthesis (Rangaraju et al., 2017; Holt et al., 2019) (Figure 1A).

\section{LOCAL TRANSLATION FOR NEURONAL HOMEOSTASIS}

Protein synthesis is an essential mechanism to ensure proper cell homeostasis. Thereby, RNA translation and protein transport to subneuronal domains have been the focus of particular concern for many researchers. Although for years it was thought that protein synthesis takes place only in the soma, it is now accepted that the transport of proteins from the soma to target subcellular regions is not the only way to supply proteins to distal neuronal processes (Alberts et al., 2002). mRNAs can also be transported to subcellular domains for their subsequent translation into proteins. This phenomenon is known as local protein synthesis (Holt et al., 2019). Taking into consideration that in some vertebrates dendrites can extend up to a dozen millimeters from the soma and that axons can measure more than one meter (Bannister and Larkman, 1995) it is not surprising that local protein synthesis serves as a means for neuronal processes to rapidly react to diverse environmental stimuli. This translation mechanism was first described in 1960 when local synthesis of acetylcholinesterase in axons was detected using isotopically labeled amino acids (Koenig and Koelle, 1960). Subsequently, some other studies were carried out in different species: local protein synthesis was also observed in isolated axons of the giant squid (Giuditta et al., 1968) and nerve fibers in goldfish (Edstrom and Sjostrand, 1969). Ever since, local protein synthesis has been studied in cells of the NS with a particular emphasis on neurons. To date, it is known that local translation is involved in axonal maintenance, guidance and arborization, and it promotes synapse formation and synaptic plasticity (Zhang and Poo, 2002; Martin, 2004; Yoon et al., 2012; Leal et al., 2014). Given that neuronal processes might as well receive environmental stimuli with potential detrimental effects, local protein synthesis also becomes relevant upon neuronal damage and in response to stress as previously reviewed (Baleriola and Hengst, 2015; Lin et al., 2020).

Although the local synthesis of acetylcholinesterase in axons was discovered by Koenig and Koelle (1960) it took two decades to detect the presence of ribosomes in neuronal peripheral processes: in 1982 polyribosomes (or polysomes) were detected for the first time in dendritic spines of neurons located in the dentate gyrus (Steward and Levy, 1982; Steward and Fass, 1983) and later, in 1986 polysomes were detected in axons (Steward and Ribak, 1986). The discovery of dendritic polysomes encouraged researchers to focus on
mRNA localization and localized translation in dendrites, and soon various dendritic transcripts were identified, such as microtubule-associated protein 2 (Map2a) (Garner and Matus, 1988), calcium/calmodulin- dependent protein kinase 2 alpha (Camk2 $\alpha$ ) (Burgin et al., 1990) or activity-regulated cytoskeletonassociated protein (Arc) (Steward et al., 1998), among others. $A c t b$ was the first transcript identified in vertebrate axons (Bassell et al., 1998) and its translation in Xenopus embryos is involved in growth cone behavior during development. Other cytoskeletonand membrane-associated proteins have more recently been identified as locally produced in rodent axons (e.g., RhoA, Par3, and SNAP25...) (Wu et al., 2005; Hengst et al., 2009; Batista et al., 2017). Transcripts encoding proteins associated with cytoskeleton and membrane dynamics are not the only locally translated in neuronal processes. Local production of proteins involved in mitochondrial function and even transcription factors have been detected in both dendrites and axons as recently reviewed by Blanco-Urrejola and colleagues (Blanco-Urrejola et al., 2021). In essence, local translation is a crucial mechanism that contributes to many neuronal functions and although this phenomenon has been mainly studied in physiological conditions it is now accepted that its deregulation is involved in various neurological diseases (Khalil et al., 2018), which we will review in this article. However, before we delve into local translation in NS pathologies, we will briefly describe the process that transcripts follow since leaving the nucleus until they get translated in target subcellular compartments.

\section{LOCAL TRANSLATION: FROM MRNA TRANSPORT TO PROTEIN SYNTHESIS}

The canonical view of protein synthesis is that mRNA translation occurs in the soma either by ribosomes associated to the rough endoplasmic reticulum (RER) (Figure $\mathbf{1 B}^{\mathrm{i}}$ ) or by free ribosomes present in the cytosol (Figure $\mathbf{1 B}^{\mathrm{ii}}$ ). The newly synthesized proteins are then processed and once mature they are transported through microtubules by dyneins and kinesins to different subneuronal domains (Figure $\mathbf{1 C}^{\mathrm{i}}$ ), where they carry out their function (Figure $\mathbf{1 D}^{\mathrm{i}}$ ). Conversely, local protein synthesis requires transcripts to leave the nucleus and bind ribonucleoprotein (RNP) granules (Figure 1B $\mathbf{B}^{\mathrm{iii}}$ ). RNP granules are then transported to target compartments (Figures 1C $^{\mathrm{ii}}$,iii) and once there, mRNAs are translated into protein (Figure $\mathbf{1 D}^{\mathrm{ii}}$ ).

\section{mRNA Transport to Neuronal Peripheral Processes}

When mRNAs exit the nucleus, RNA binding proteins (RBPs) recognize specific localization elements typically found in the $3^{\prime}$-Untranslated Regions (3'-UTR) of the transcripts known as zip codes (Perry and Fainzilber, 2011; Szostak and Gebauer, 2013; Berkovits and Mayr, 2015). Interestingly, evidence suggest that long $3^{\prime}$-UTRs provide a longer life span to RNAs favoring their long distance transport and hence their localization to peripheral neuronal processes (Tushev et al., 2018). Besides binding the transcripts, RBPs associate with translation regulators including ribosomal proteins and other 


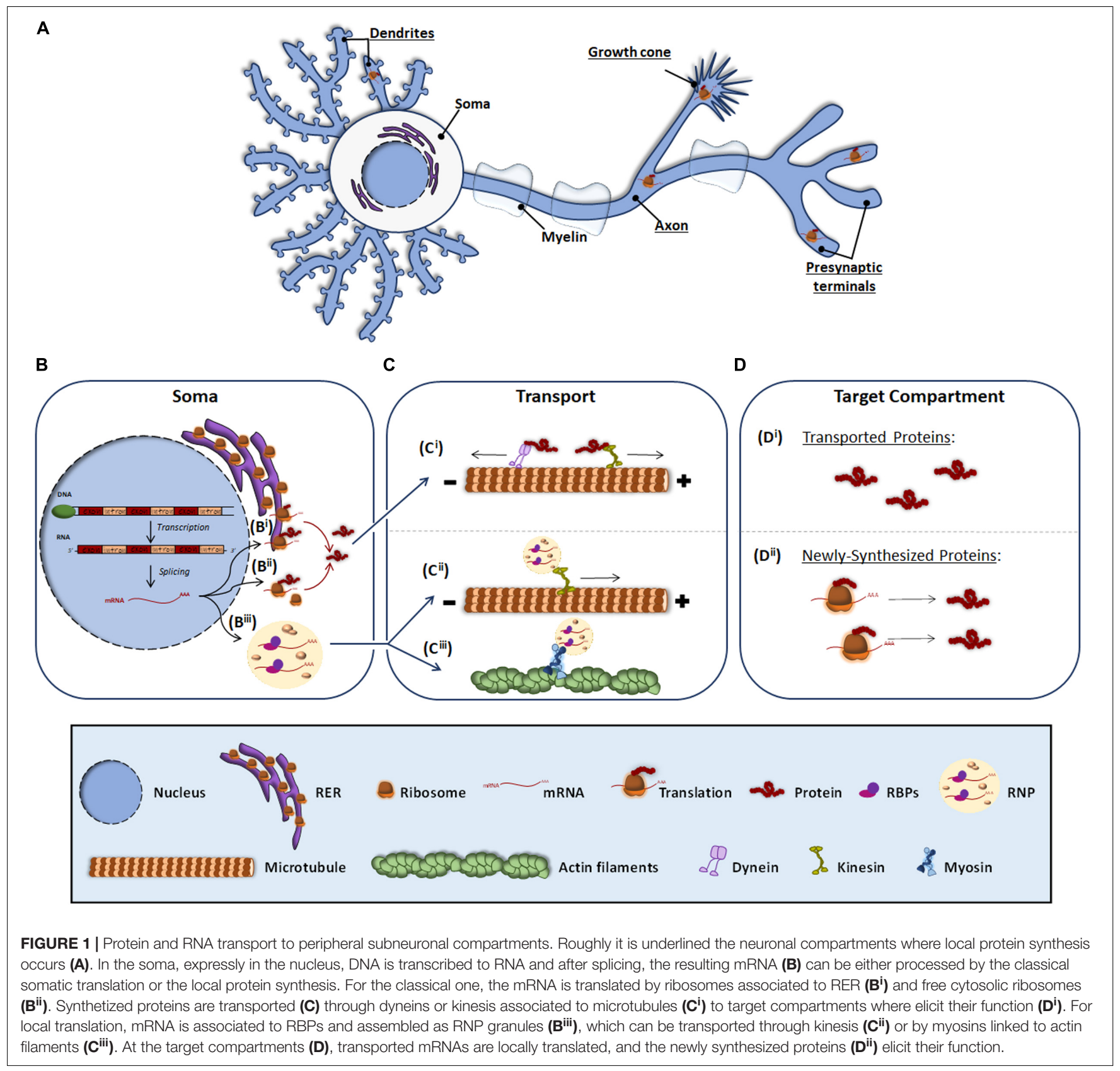

components of the translation machinery, ribosomal RNAs, and non-coding RNAs (Kim et al., 2005; Skup, 2008), and assemble into membraneless RNPs (Formicola et al., 2019; Pushpalatha and Besse, 2019; Figure 1B ${ }^{\text {iii }}$ ). RNPs bind to motor proteins directly or indirectly via adapters and the transport of the transcripts to distal compartments is initiated. Depending on the target compartment, transport occurs via microtubules bound to kinesins (in the case of axons and dendrites) (Dixit et al., 2008; Guillaud et al., 2020; Figure 1C ii $^{\text {) }}$ or through actin microfilaments associated to myosin (in axonal growth cone, presynaptic terminals and dendritic spines) (Hirokawa et al., 2010; Shirao and Gonzalez-Billault, 2013; Craig, 2018; Figure $\left.1^{\mathrm{iii}}\right)$. During transport, RNP granules participate in the repression of translation but they are also involved in the local translation of proteins when remodeling of the RNP granules occurs driven by external signals. Interestingly, recent evidence indicates that RNP granules bind to membranous organelles located in axons such as endosomes and mitochondria, which serve as platforms to aid with local protein synthesis (Baumann et al., 2014; Cioni et al., 2019).

\section{Local Protein Synthesis in Subcellular Compartments}

As in the soma, the ribosomes are the molecular machines responsible for protein synthesis in subcellular domains. For 


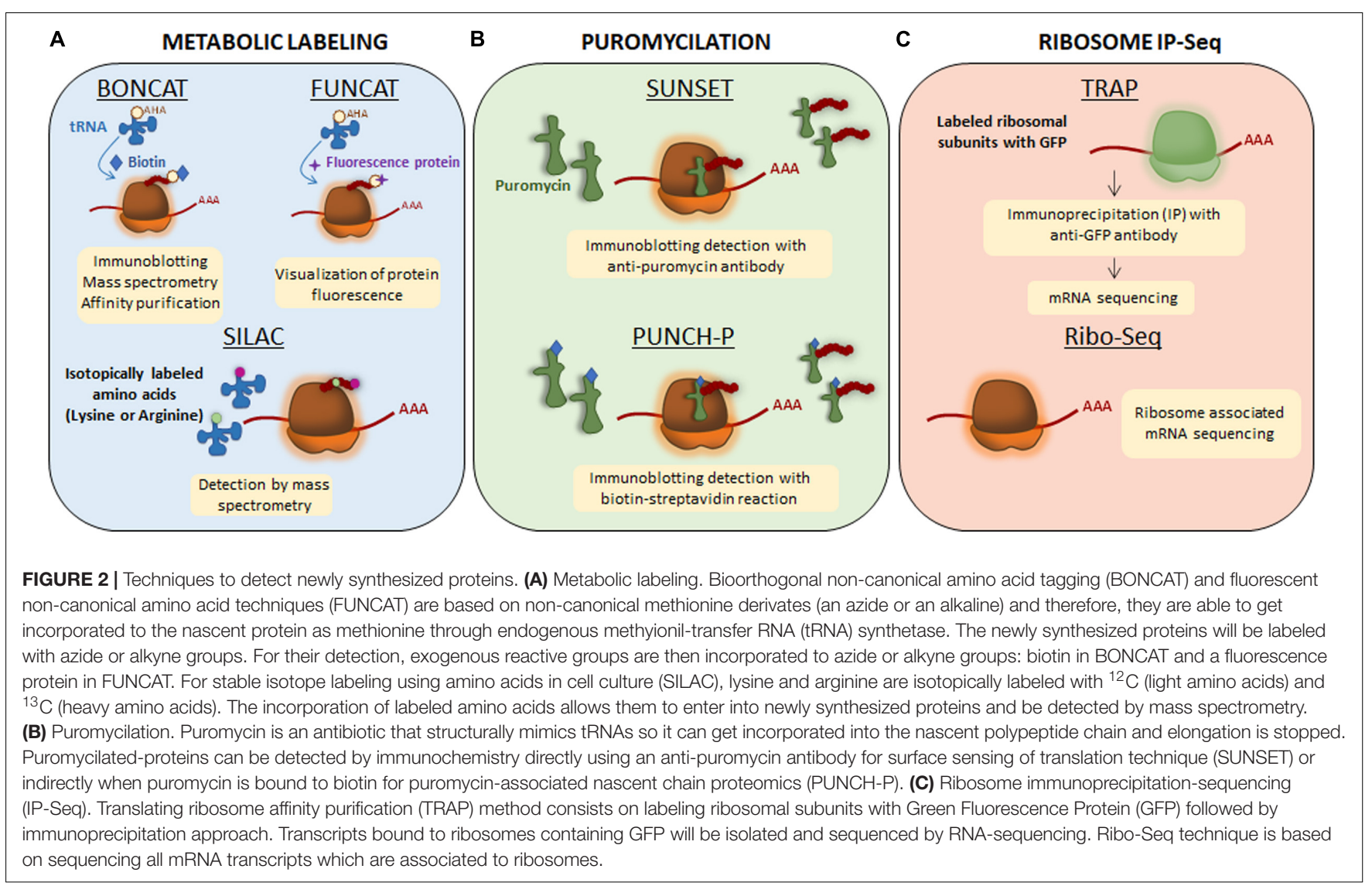

many years it was assumed that ribosomes were translationally active when associated forming polysomes, as these structures where the first detected in dendrites and axons (Steward and Levy, 1982; Steward and Fass, 1983; Steward and Ribak, 1986). However, a recent study has published the existence of both polysomes and monosomes in synaptosomes. This same study suggests that while in the soma the vast majority of transcripts associate to polyribosomes, most synaptic mRNAs bind to and are translated by monosomes compared to a few synaptic transcripts that preferentially bind polysomes (Biever et al., 2020).

Local translation, like any other cellular process, requires energy. Recently, Rangaraju et al. (2019) described that mitochondrial compartments present in dendrites contribute to synaptic plasticity by supplying the energy required to synthesize proteins in spines. However, some subneuronal domains (e.g., the presynaptic terminals) do not contain mitochondria and the energy demands are met by local ATP produced by synaptic cycles in response to neuronal activity (Rangaraju et al., 2014). Independently on how subcellular compartments provide the necessary energy for protein synthesis, transcripts are considered locally translated if they meet the following requirements: (1) coding transcripts to be translated need to colocalize with ribosomes and other components of the translation machinery in a given subcellular domain, (2) newly synthesized proteins need to be detected at subcellular levels by techniques such as protein metabolic labeling (Figure 2A), puromycilation of nascent peptides (Figure 2B) or ribosome immunoprecipitation followed by sequencing (Figure 2C), and (3) levels of newly synthesized proteins need to drop when blocking protein synthesis (e.g., with pharmacological inhibitors such as anisomycin or emetine) (Holt et al., 2019).

\section{LOCAL TRANSLATION IN NERVOUS SYSTEM PATHOLOGIES}

Since the study of the first proteins synthesized in different subneuronal domains, most research has focused on discovering new localized transcripts in neurons. However, there was no evidence linking local synthesis deregulation with neuronal pathologies until 2001 when Zheng and colleagues described that intra-axonal RNA translation was activated in response to nerve injury (Zheng et al., 2001). From then on, there is growing evidence on the translation of localized transcripts upon nerve injury and on the role of locally produced proteins in the response of neurons to damage. For instance, the axonal synthesis of the transcription factors STAT3 and PPAR $\gamma$ after sciatic nerve crush is followed by their retrograde transport toward the neuronal cell body. Once there, both STAT3 and $\operatorname{PPAR} \gamma$ trigger transcriptional programs contributing to nerve regeneration (Ben-Yaakov et al., 2012). Interestingly, at least one component of the importin $\alpha / \beta$ complex required for retrograde transport is also synthesized in injured axons (Hanz et al., 2003). These data point at the implication of local 
translation in neuronal survival following nerve lesions in the peripheral nervous system. In addition, a deregulation of local protein synthesis upon damage was also recently suggested in the central nervous system. In retinal ganglion cells, the RBP RBPMS is expressed exclusively in the soma but upon hypoxia and axotomy, RBPMS is redistributed to dendrites and axons, respectively (Pereiro et al., 2020). Authors have also identified alterations of various RBPs in different neurological diseases, including amyotrophic lateral sclerosis, frontotemporal dementia or spinal muscular atrophy. Likewise, in other disorders such as Alzheimer's disease, deregulation of translation of certain mRNAs in neuronal processes seems to contribute to the pathology. We will now summarize the current knowledge on how deregulation of local protein synthesis at different levels can contribute to the development and progression of NS pathologies (Table 1).

\section{Amyotrophic Lateral Sclerosis (ALS) and Frontotemporal Dementia (FTD)}

Amyotrophic lateral sclerosis is the most common motor neuron disease with an adult onset and it is characterized by the degeneration of upper and lower motor neurons. Most of ALS patients -around 90\%- suffer the sporadic form of the disease whereas the remaining $10 \%$ of the cases correspond to familial ALS with a genetic inheritance (Scotter et al., 2015). Different genes have been associated to ALS pathology including those encoding for $\mathrm{Cu}-\mathrm{Zn}$ superoxide dismutase 1 (SOD1), Tar DNA binding-protein 43 (TDP-43), fused in sarcoma/translocated in liposarcoma (FUS), or chromosome 9 open reading frame 72 (C9orf72). Interestingly, some of the ALS-linked genes have also been related to FTD. FTD is a group of disorders whose main feature is the loss of neurons in frontal and temporal brain lobes leading to cognitive impairment. Similarly to ALS, FTD is mainly a sporadic disorder although $40 \%$ of cases have family history with a $10 \%$ of autosomal dominant inheritance (Bott et al., 2014). In this section we will review the ALS/FTDassociated genes involved in mRNA localization and translation within neurites.

Tar DNA binding-protein-43 is an RBP involved in mRNA splicing, transport and translation in neuronal processes. The presence of TDP-43 aggregates in the cell cytoplasm in ALS and FTD patients has been reported. TDP-43 associates to specific mRNAs in RNP granules and transports them to the target neuronal compartment where mRNAs can be translated by the localized translation machinery (Alami et al., 2014). In 2014, futsch mRNA was identified as a TDP-43 target in a Drosophila ALS model. Futsch is known to be involved in the development and maintenance of synaptic contacts at the neuromuscular junctions (NMJ). Mutant TDP-43 alters futsch localization: mRNA levels are significantly reduced at the NMJ while higher levels are detected in neuronal somata. In addition to mislocalization, TDP-43 also regulates futsch translation by shifting mRNA from actively translating polysomes to non-translating ribonuclear protein particles. Similarly, the mammalian homolog of Futsch, MAP1B accumulates in motor neuron cell bodies in the spinal cord from ALS patients (Coyne et al., 2014). As both Futsch and MAP1B are part of the microtubule cytoskeleton, defects in their local translation due to mutant TDP-43 could lead to cytoskeletal defects, contributing to ALS development (as summarized in Figure 3A).

Another important RBP linked to ALS and FTD is FUS, which, as TDP-43, plays a role in RNA metabolism (splicing, trafficking and translation). FUS also appears in cytoplasmic inclusions in diseases. However, it was reported that FUS deposits are post-translationally modified by arginine unmethylation only in postmortem tissue from FTD patients but not in ALS ones. Indeed, FUS hypomethylation triggers its aggregation and consequently alters RNP granules and local protein synthesis in neurites (Qamar et al., 2018). On the other hand, wild type FUS is present in somata and along neuronal processes as well, including dendrites, spines and the NMJ. Specifically, FUS has been detected at translation sites in axons. ALSlinked mutations in FUS lead to its accumulation in neurites of hippocampal and sciatic nerve neurons. Moreover, mutant FUS leads to stress-mediated inhibition of intra-axonal protein synthesis and therefore to synaptic dysfunction (Lopez-Erauskin et al., 2018; Figure 3A). In fact, a previous study had already reported the incorporation of cytoplasmic mutant FUS into stress granules (Bosco et al., 2010). Some FUS target mRNAs are abnormally expressed when FUS is mutated. For instance, Fos$B$ is upregulated in axons in FUS-mutant motor neurons causing an increase in axonal branching. The axonal morphology can be rescued by the suppression of exacerbated Fos- $B$ expression by locally applying siRNAs to axons. Interestingly, an abnormal Fos$B$ upregulation in ventral horn neurons in ALS autopsy samples has also been reported (Akiyama et al., 2019).

In addition to the contribution to intra-axonal translation, both FUS and TDP-43 are also localized to dendrites and dendritic spines (Swanger and Bassell, 2013). Furthermore, TDP43 does not only regulate mRNA translation but is also involved in dendritic mRNA trafficking (Chu et al., 2019).

Notably, an interaction between FUS and TDP-43 was identified in 2010. It is of interest to highlight that this FUS/TDP-43 association is enhanced by ALS-linked mutant variants in TDP-43 (Ling et al., 2010). Therefore, this report reveals the possible convergence of pathogenic mechanisms from both FUS and TDP-43 in ALS. Similarly, other interactions between proteins associated to NS disorders have been identified. TDP-43 seems to interact to disrupted in schizophrenia 1 (DISC1) in brains of both FTD mouse model and patients. The TDP-43/DISC1 complex negatively regulates dendritic local translation in response to neuronal activity. This association might explain some psychiatric behaviors observed in FTD patients since DISC1 is a relevant player in the pathology of psychiatric disorders (Endo et al., 2018). In the case of FUS, it interacts with the survival motor neuron protein (SMN), the main responsible for the development of spinal muscular atrophy (SMA). The relationship between both disease-linked proteins will be discussed in the next paragraph corresponding to SMA.

The GGGGCC repeat expansion in the C9orf72 gene is associated to a significant percentage of familial ALS cases. Although C9orf72 function remains unclear, authors have demonstrated that the repeat expansion can form G-quadruplexes, which are known to participate in splicing, 
TABLE 1 | Summary of altered proteins and mRNAs involved in local translation in different nervous system pathologies.

\begin{tabular}{|c|c|c|c|c|}
\hline Disease & Protein/mRNA & $\begin{array}{l}\text { Altered mechanism on local } \\
\text { translation }\end{array}$ & Model system & References \\
\hline \multirow[t]{3}{*}{ ALS/FTD } & TDP-43 & $\begin{array}{l}\text { Abnormal trafficking of futsch/Map } 1 b \\
\text { mRNAs to neurites leading to } \\
\text { cytoskeleton defects }\end{array}$ & $\begin{array}{l}\text { Drosophila model of ALS in vivo, ALS } \\
\text { vs. control postmortem brain tissue }\end{array}$ & Coyne et al., 2014 \\
\hline & FUS & $\begin{array}{l}\text { Stress-mediated inhibition of } \\
\text { intra-axonal translation }\end{array}$ & $\begin{array}{l}\text { HEK-293 cell line and zebrafish embryo } \\
\text { spinal cords; mutant FUS mice and } \\
\text { mouse hippocampal neuron culture }\end{array}$ & $\begin{array}{l}\text { Bosco et al., 2010; Lopez-Erauskin } \\
\text { et al., } 2018\end{array}$ \\
\hline & C9orf72 & $\begin{array}{l}\text { mRNP granules mislocalization to } \\
\text { neuritic compartments affecting to } \\
\text { branching }\end{array}$ & $\begin{array}{l}\text { Rat spinal cord neuron culture, } \\
\text { Drosophila model in vivo }\end{array}$ & Burguete et al., 2015 \\
\hline SMA & SMN & $\begin{array}{l}\text { Actb, Nrn1, Gap43, Anxa2 } \\
\text { mislocalization altering neurite growth, } \\
\text { presynaptic function, and cytoskeleton } \\
\text { Repression of axonal mTOR through } \\
\text { miR-183 }\end{array}$ & $\begin{array}{l}\text { NSC-34 cell line; mouse motor neuron } \\
\text { culture } \\
\text { Rat hippocampal, cortical, and motor } \\
\text { neuron culture }\end{array}$ & $\begin{array}{l}\text { Rage et al., 2013; Fallini et al., 2014, } \\
2016 \text {; Kye et al., 2014; Rihan et al., } \\
2017\end{array}$ \\
\hline \multirow[t]{2}{*}{$A D$} & Mapt & $\begin{array}{l}\text { Mapt mislocalization to dendrites and } \\
\text { hyperphosphorylation }\end{array}$ & $\begin{array}{l}\text { Mouse hippocampal neuron culture, } \\
\text { WT vs. Tau KO mice; hippocampal } \\
\text { neuron culture from WT and Fyn KO } \\
\text { mice, HEK-293 cell line, WT, APP23 } \\
\text { and FynCA Tg mouse models in vivo }\end{array}$ & $\begin{array}{l}\text { Kobayashi et al., 2017; Li and Gotz, } \\
2017\end{array}$ \\
\hline & Atf4 & $\begin{array}{l}\text { Atf } 4 \text { recruitment to axons induced by } \\
\text { A } \beta \text { oligomers, leading to neuronal death }\end{array}$ & $\begin{array}{l}\text { Rat hippocampal neuron culture, } \\
\text { mouse model in vivo, AD and control } \\
\text { postmortem human brain tissue }\end{array}$ & $\begin{array}{l}\text { Baleriola et al., 2014; Walker et al., } \\
2018\end{array}$ \\
\hline \multirow[t]{3}{*}{ PD } & UPR genes & $\begin{array}{l}\text { UPR altered. } \\
\text { A compartment-dependent UPR } \\
\text { involving local translation? }\end{array}$ & $\alpha$-synuclein Tg mice & Hetz and Saxena, 2017 \\
\hline & LRRK2 & $\begin{array}{l}\text { Deregulation of global elF4E/4E-BP. } \\
\text { Defects in axonal 4E-BP dependent } \\
\text { translation? } \\
\text { Axonal microRNAs deregulation? }\end{array}$ & $\begin{array}{l}\text { HEK-293 and SH-SY5Y cell lines; rat } \\
\text { superior cervical ganglia neuron culture; } \\
\text { rat cortical neuron culture, WTvs. } \\
\text { LRRK2 KO mice }\end{array}$ & $\begin{array}{l}\text { Imai et al., 2008; Kumar et al., 2010; } \\
\text { Natera-Naranjo et al., 2010; Herzig } \\
\text { et al., 2011; Trancikova et al., } 2012\end{array}$ \\
\hline & PINK1/PARK2 & $\begin{array}{l}\text { Pumilio and Glorund/hnRNP-F } \\
\text { displacement: altered translation in the } \\
\text { mitochondrion surface (within axons?) } \\
\text { due to PINK1/PARK2 mutations. }\end{array}$ & $\begin{array}{l}\text { Drosophila PINK1 model and HEK } \\
\text { 293T cell line }\end{array}$ & $\begin{array}{l}\text { Mouton-Liger et al., 2017; Martinez } \\
\text { et al., } 2019\end{array}$ \\
\hline $\mathrm{HD}$ & $\mathrm{HTT}$ & $\begin{array}{l}\text { Impaired dendritic levels of Actb mRNA, } \\
\text { Ago2 protein and P-bodies } \\
\text { Altered axonal BDNF delivery leading to } \\
\text { neurotoxicity }\end{array}$ & $\begin{array}{l}\text { Homozygous Htt mutant cell lines } \\
\text { (109Q/109Q); HeLa S3 cells } \\
\text { Flagged-Htt590; rat cortical neuron } \\
\text { culture and brain sections }\end{array}$ & $\begin{array}{l}\text { Gauthier et al., 2004; Savas et al., } \\
\text { 2008; Ma et al., 2010, 2011; Savas } \\
\text { et al., } 2010\end{array}$ \\
\hline ASD and FXS & FMRP & $\begin{array}{l}\text { Deregulation of local mRNAs linked to } \\
\text { abnormal spine morphology and } \\
\text { plasticity } \\
\text { Upregulation of dendritic Dlg4 } \\
\text { translation through inhibition of } \\
\text { miR-125a with spine morphology } \\
\text { defects } \\
\text { Dendritic mTOR upregulation }\end{array}$ & $\begin{array}{l}\text { Rat hippocampal neuron culture; } \\
\text { cortical neuron culture from Fmr1 KO } \\
\text { mice; in vivo Fmr1 KO mouse model; } \\
\text { Organotypic hippocampal slice cultures } \\
\text { from Fmr1 KO mice }\end{array}$ & $\begin{array}{l}\text { Antar et al., 2004; Muddashetty et al., } \\
\text { 2011; Pyronneau et al., 2017; Banerjee } \\
\text { et al., 2018; Feuge et al., } 2019\end{array}$ \\
\hline \multirow[t]{2}{*}{ DS } & Dscam & $\begin{array}{l}\text { Upregulation of dendritic mRNA and } \\
\text { protein levels with defects in dendrite } \\
\text { branching }\end{array}$ & $\begin{array}{l}\text { Mouse hippocampal neuron culture } \\
\text { from Ts1Cje mice, DS mouse model }\end{array}$ & Alves-Sampaio et al., 2010 \\
\hline & $B d n f$ & $\begin{array}{l}\text { Upregulation within dendrites leading to } \\
\text { an aberrant activation of dendritic } \\
\text { translation }\end{array}$ & $\begin{array}{l}\text { In vitro hippocampal dendrites from } \\
\text { Ts1Cje mice }\end{array}$ & $\begin{array}{l}\text { Troca-Marin et al., 2011; Swanger and } \\
\text { Bassell, } 2013\end{array}$ \\
\hline \multirow[t]{2}{*}{ Other } & $\begin{array}{l}\text { Bdnf (depression } \\
\text { and bipolar } \\
\text { disorder) }\end{array}$ & $\begin{array}{l}\text { Dendritic Bdnf localization to dendrites } \\
\text { disrupted }\end{array}$ & $\begin{array}{l}\text { Ts1 Cje mouse hippocampal neuron } \\
\text { culture }\end{array}$ & Swanger and Bassell, 2013 \\
\hline & Pumilio-2 (epilepsy) & $\begin{array}{l}\text { Erroneous mRNAs localization to axons } \\
\text { Upregulation of overall translation in } \\
\text { axons with branching defects }\end{array}$ & $\begin{array}{l}\text { In vivo } 5 \text { month Pum2 gene-trap mice; } \\
\text { Pum2 knockdown in primary dorsal } \\
\text { root ganglion rat neuron culture and } \\
\text { mouse model in vivo }\end{array}$ & $\begin{array}{l}\text { Follwaczny et al., 2017; Martinez et al., } \\
2019\end{array}$ \\
\hline
\end{tabular}

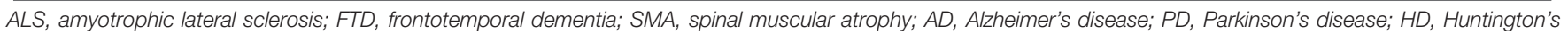
disease; $A S D$, autism spectrum disorders; FXS, fragile-X syndrome; DS: down syndrome. 
A AMYOTROPHIC LATERAL SCLEROSIS (ALS) AND FRONTOTEMPORAL DEMENTIA (FTD)

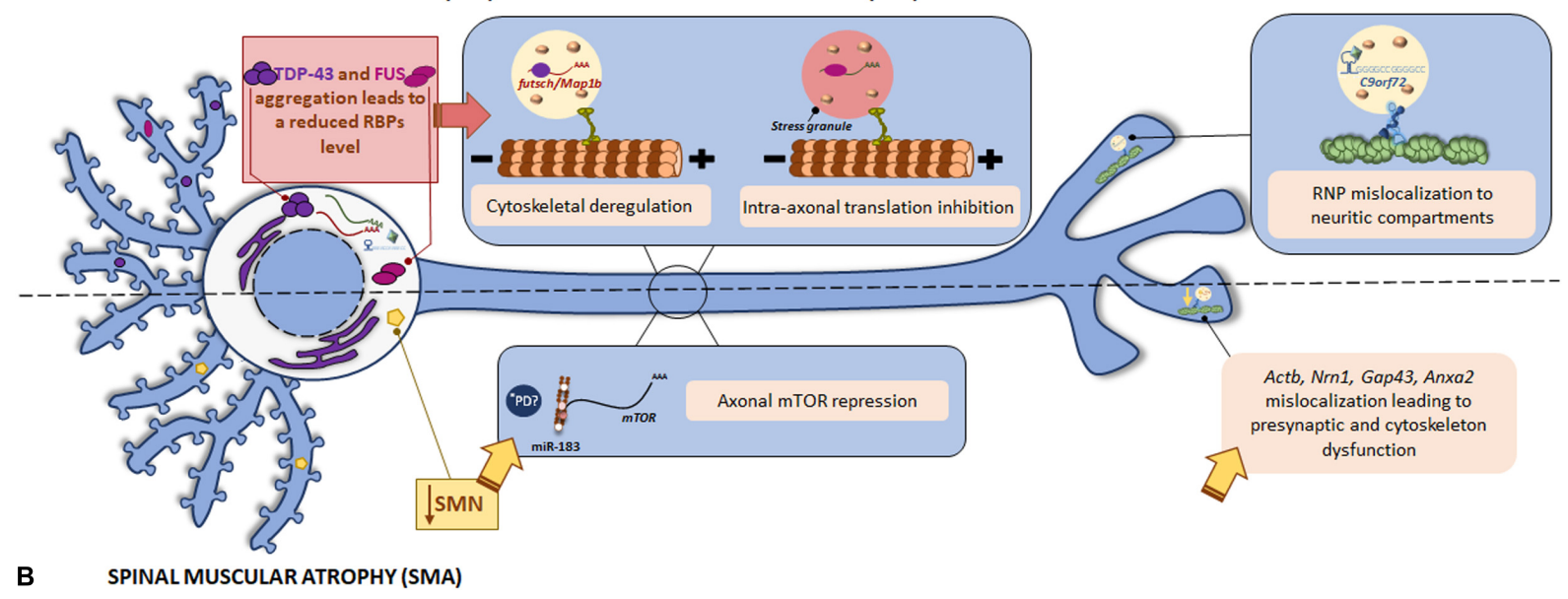

FIGURE 3 | Local translation defects in ALS/FTD and SMN. (A) Among ALS/FTD-linked proteins, TDP-43, FUS, and C9orf72 are found. The RBPs TDP-43 and FUS play a role in RNA metabolism. The aggregates usually found in ALS and FTD patients impair TDP-43 and FUS function leading to altered mRNA localization and the consequent cytoskeletal deregulation and stress-mediated intra-axonal translation inhibition, respectively. The GGGCC repeat expansion in the C9orf72 mRNA triggers its assembly in RNP granules, which are erroneously localized to neuritic compartments and affect to nerve branching. (B) Loss of SMN is the main cause of SMA. SMN is involved in the localization of mRNAs to the axonal compartment. SMN defects lead to Actb, Nrn1, Gap43, and Anxa2 mislocalization with important impact in neurite growth, presynaptic function, and cytoskeleton plasticity. SMN also controls the regulator of local translation mTOR through miR-183. *PD miRNAs are also involved in the translation repression induced by mutant LRRK2 in PD. Due to local miRNAs have been identified as contributors to other pathologies, a similar local mechanism could participate in the pathogenesis of PD.

mRNA trafficking and translation regulation (Fratta et al., 2012). In addition, GGGGCC repeat RNAs are assembled into mRNA transport granules and wrongly localized to neuritic compartments. The consequent mislocalization of mRNA granules alters nerve branching (Figure 3A). These observations suggest a novel mechanism underlying neuronal defects in disease-associated expanded repeats like ALS (Burguete et al., 2015).

As mentioned above, late endosomes act as platforms for local protein synthesis in axons and dendrites. Moreover, other organelles, including mitochondria or lysosomes, can be "vehicles" for RNP granule transport and localization. ANXA11 is an RNA granule-associated protein that acts as an adaptor between lysosomes and RNP granules. ALS-associated mutations in ANXA11 prevents RNP granule association to lysosomes and impaired RNP transport which results in altered RNA localization to axons what might contribute to axonal degeneration in ALS (Liao et al., 2019).

Together, these findings underline the relevance of a correct localization of mRNAs for neuronal physiology: while mutant forms of the RBPs TDP-43 and FUS alter localization of certain mRNAs within neurites and lead to the consequent impairment on cytoskeleton and synapses, the defective localization of mRNA granules in neurites caused by the GGGGCC repeat expansion in C9orf72 results in altered branching (Figure 3A and Table 1).

\section{Spinal Muscular Atrophy (SMA)}

Spinal muscular atrophy is another example of a motor neuron disease in which both RBP deregulation and mRNA mislocalization have been reported. SMA is an autosomal disorder characterized by the progressive loss of spinal motor neurons and skeletal muscle atrophy. Mutations in the SMN1 gene leading to reduced SMN levels haven been identified as the cause of SMA pathology. SMN is a ubiquitously expressed RBP whose main function is the assembly of small nuclear RNPs for mRNA splicing. However, neuronal SMN is also involved in the assembly of RNP complexes required for mRNA transport to axons and for local translation. Fallini and colleagues described that the association of SMN to messenger RBPs (mRBPs) such as $\mathrm{HuD}$ and IMP1 is involved in the localization of poly $(\mathrm{A})$ mRNAs to the axonal compartment (Fallini et al., 2011, 2014). Defects in axonal SMN thus lead to mRNA mislocalization. Among mislocalized mRNAs, some relevant for neurite growth and presynaptic function can be found, including Actb, Nrn1, and Gap43, to mention but a few. For instance, Gap43 is reduced in growth cones of SMA motor neurons at mRNA and protein levels. Interestingly, $\mathrm{HuD}$ and IMP1, both of them altered by defects in SMN, control the transport of Gap43 mRNA. Conversely, the overexpression of these mRBPs is sufficient to restore axon growth (Fallini et al., 2016). Likewise, 50\% of SMN reduction impairs the localization of other mRNAs such as Anxa2 (encoding Annexin A2) and Cox4i2 (Rage et al., 2013). Annexin A2 is involved in actin cytoskeleton plasticity. The observed defects in cytoskeleton organization in SMN deficiency models could be explained at least in part by the mislocalization of Anxa2 and its consequent impaired axonal translation (Rihan et al., 2017). Altogether, these data suggest that deregulation of mRNA localization to axonal compartments and local protein synthesis are key players in the development of SMA pathology. 
Survival motor neuron protein also controls local translation through microRNA (miR) expression. In SMN-deficient neurons, miR-183 is increased in neurites. miR-183 targets axonal mTOR, a master regulator of local protein synthesis, leading to reduction of its own translation. Therefore, overall mTORdependent local translation is decreased in SMN-deficient axons (Kye et al., 2014).

We have mentioned in previous paragraphs the existent interaction between proteins associated to different neurodegenerative diseases. A 2013 study identified FUS, one of the ALS/FTD-linked RBPs, as an interactor of SMN. The association between both RBPs appears to be influenced by FUS mutations and leads to a redistribution of SMN toward FUS deposits with the consequent impairment in axonal localization of SMN (Groen et al., 2013). Moreover, there is evidence of the association of SMN and FMRP (fragile $\mathrm{X}$ mental retardation protein, involved in Fragile $\mathrm{X}$ syndrome) in neuronal mRNP granules (Piazzon et al., 2008).

To summarize, SMN contributes to local protein synthesis regulation through its interaction with RBPs and the control of miRNAs. Therefore, mutations in this protein result in mRNA mislocalization and repression of axonal translation (Table 1). The data reviewed so far overall suggest that dysfunction of RBPs and the consequent mRNA mislocalization alter localized translation and underly the pathophysiological features of motor neuron diseases as depicted in Figure 3B.

\section{Alzheimer's Disease (AD)}

Alzheimer's disease is the most common cause of dementia among the elderly. It is an incurable neurodegenerative disease characterized by the gradual loss of cognitive and functional abilities. Pathological cellular dysfunction in AD begins many years before the onset of the symptoms. Two hallmarks have been identified in postmortem brains as main contributors to $\mathrm{AD}$ pathology: the neurofibrillary tangles, composed of hyperphosphorylated microtubule associated protein Tau (MAPT or Tau) and the extracellular $\beta$-amyloid $(\mathrm{A} \beta)$ plaques (Tiwari et al., 2019; Busche and Hyman, 2020). Although the mechanisms leading to the development and spread of the disease through the brain are not fully understood, it is known that synapse loss is one of the first pathological signs of $\mathrm{AD}$ (Selkoe, 2002). Alterations in the axonal and dendritic proteomes could underlie synaptic dysfunction and thereby the study of local protein synthesis in this context might provide clearer knowledge on the development of the disease.

Tau is mainly localized to axons though is also present in the somatodendritic compartment at very low levels in healthy neurons (Tashiro et al., 1997). Axonal Tau is partially the product of locally translated Mapt mRNA (Aronov et al., 2001; Gauthier-Kemper et al., 2018). Nevertheless, Mapt gets aberrantly localized to dendrites in tauopathies such as AD. For instance, $\mathrm{A} \beta$ peptides induce Mapt mRNA localization to dendrites and its localized translation. Intriguingly, the mislocalization and dendritic synthesis of Tau enhances its hyperphosphorylation (Kobayashi et al., 2017; Li and Gotz, 2017), indicating that Tau synthesis in the inappropriate subneuronal compartment contributes to neurodegenerative diseases such as AD.
$\mathrm{A} \beta$ peptides are the result of incorrect proteolytic cleavage of amyloid precursor protein (APP) and are prone to aggregate, which results in the formation of senile plaques (Rabbito et al., 2020). We have stated that $A \beta$ triggers Tau synthesis in dendrites but it also induces local protein synthesis in axons (Baleriola et al., 2014; Gamarra et al., 2020). The mRNA encoding the transcription factor ATF4 (previously known as CREB2) is among the proteins whose local translation is induced by $A \beta$ peptides. Interestingly, axonally synthesized ATF4 is retrogradely transported to the nucleus where it alters transcription leading to neuronal death both in vitro and in vivo (Baleriola et al., 2014; Figure 4A). Additionally, Atf4 recruitment to $A \beta$-exposed axons is itself triggered by local translation of sentinel mRNAs such as the intermediate filament protein vimentin (Vim) (Walker et al., 2018). These studies suggest a common axon-to-soma communication mechanism in injured nerves and in response to amyloid based on axonally synthesized transcription factors although the outcome of the transcriptional response differs: a regenerative response of injured nerves vs. neuronal death following the local exposure to $A \beta$ oligomers.

Atf4 is not the only mRNA found in A $\beta$-treated axons. Interestingly, transcripts from 9 of the 20 susceptibility genes associated to late onset $\mathrm{AD}$ are axonally localized following exposure to A $\beta$ oligomers: App, Clu, ApoE, Sorl1, Bin1, Picalm, Ptk2, Celf1, and Fermt2 (Blanco-Urrejola et al., 2021).

Local translation has also been described in other neural cells like oligodendrocytes. For example, the heterogeneous nuclear RNP A2 (hnRNP A2) is part of the transport granules responsible for mRNA localization to peripheral processes in oligodendrocytes (Hoek et al., 1998; Munro et al., 1999). Intriguingly, loss of hnRNP A/B in entorhinal cortices from AD brains has been reported. Experiments performed in neurons indicate that defects in hnRNP A/B lead to dendritic loss in vitro and memory and electrocorticographic alterations in vivo (Berson et al., 2012). Based on the role of hnRNP A2 in oligodendrocytes a possible involvement of hnRNP A/B in neuronal mRNA metabolism cannot be discarded. Further investigation should be carried out in order to fully understand the role of hnRNPs in RNA localization and protein synthesis in neuronal processes in disease.

Regarding interaction between proteins associated to different NS pathologies, in $50 \%$ of FTD cases an accumulation of Tau fibrils has been observed (Goedert et al., 2012). Interestingly, reduced levels of the ALS/FTD-linked TDP-43 are detected in the AD brain. Indeed, TDP-43 promotes Mapt mRNA instability through its $3^{\prime}$-UTR, suggesting that altered TDP-43 might contribute to Tau aggregation ( $\mathrm{Gu}$ et al., 2017). Taking into account that axonal localization signals are usually located at the $3^{\prime}$-UTR, we can speculate that deregulation of TDP-43 also affects Tau localization and therefore might also contribute to Tau pathology in FTD.

Results reviewed in these paragraphs strongly point toward the importance of mRNA localization and localized translation and/or deregulation of both phenomena in the development of $\mathrm{AD}$ and related disorders. One of the main hallmark of $\mathrm{AD}$, A $\beta$ aggregates, lead to deregulation of local protein synthesis in both dendrites and axons. These events contribute to Tau 


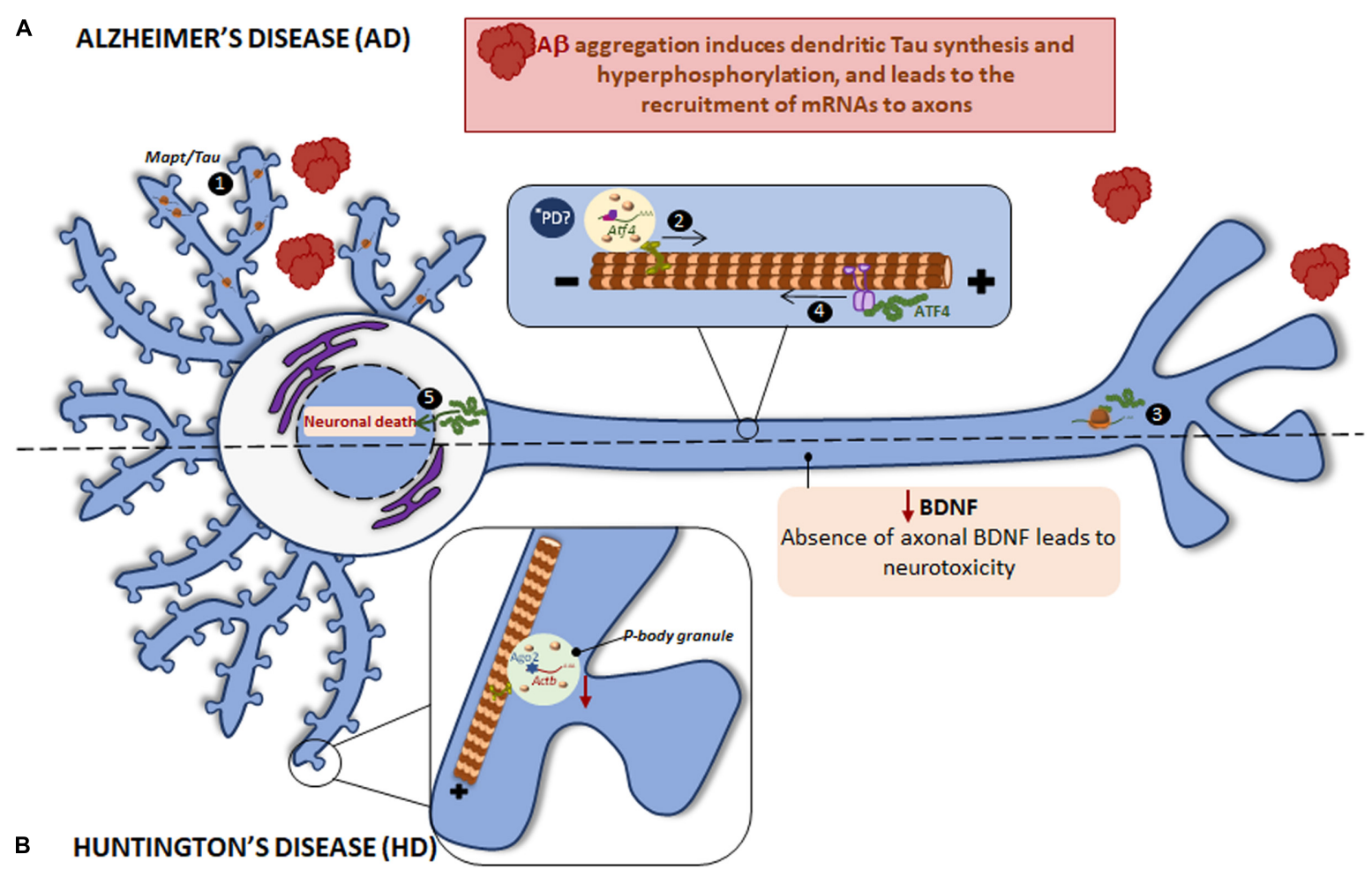

FIGURE 4 | Local translation defects in AD and HD. (A) The two main hallmarks in AD brains are the accumulation of intracellular hyperphosphorylated Tau and extracellular $A \beta$ plaques. $A \beta$ induces the incorrect localization of Mapt mRNA to dendrites with the consequent, local synthesis of Tau and its hyperphosphorylation (1). A $\beta$ also induces the recruitment of certain mRNAs to axons, among them Atf4 is found (2). Once ATF4 is axonally synthesized (3), it is retrogradely transported to cell body (4) where enhances death transcriptional programs (5). *PD ATF4 is also a component of UPR. The UPR is altered in PD and therefore the local ATF4 could be involved in PD progression. (B) HD is caused by a mutant CAG expansion in HTT gene. HTT KO leads to reduced levels of Actb mRNA, Ago2 protein, and p-bodies in dendrites. Mutant HTT impairs BDNF transport to axons resulting in neurotoxicity and probably affects to local protein synthesis since BDNF regulate this process in subneuronal compartments.

hyperphosphorylation and neuronal death respectively (Table 1). Thus, restoring levels of localized mRNAs and/or their localized translation could alleviate cell dysfunction linked to AD.

\section{Huntington's Disease (HD)}

Huntingtin (HTT) is a protein expressed at high levels in several brain regions like the hippocampus, the cortex, the cerebellum and the striatum. CAG repeat expansions in the HTT gene result in a repeated polyQ tract in the $\mathrm{N}$-terminal region of the HTT protein, causing HD. HD is an autosomal dominant neurodegenerative disease characterized by uncontrolled movements, and behavior and cognitive impairments (Landles and Bates, 2004; Li and Li, 2004). HTT, as well as APP, is transported along axons and has been implicated in dendritic RNA delivery (Ma et al., 2010; Savas et al., 2010). Importantly, HTT inactivation leads to impaired localization of RNAs and membranous organelles (Gauthier et al., 2004), indicating that HTT plays an important role in RNA transport.

Similar to other previously mentioned neurodegenerative disorders, RBPs colocalize with the main driver of HD: HTT interacts with Ago2 and Staufen in processing bodies (P bodies) which contain translationally repressed mRNAs (Savas et al., 2008), and in dendritic RNA granules involved in transport and local translation (Savas et al., 2010). Additionally, HTT was reported to bind to the $3^{\prime}$-UTR of dendritically targeted mRNAs including Ip3r1, Actb, and Bdnf. Moreover, HTT knockout (KO) reduces levels of dendritic Actb mRNA, Ago2 protein, and P bodies (Ma et al., 2010, 2011; Savas et al., 2010). HTT is also required for BDNF vesicular transport along microtubules toward the axons. Mutant HTT impairs BDNF transport leading to neurotoxicity (Gauthier et al., 2004) (as summarized in Figure 4B). Noteworthy, BDNF is known to regulate local translation (Swanger and Bassell, 2013) and thus local protein synthesis in HD might be impaired via defective axonal BDNF delivery.

Huntingtin is thus yet another example of a main contributor to NS pathology involved in mRNA trafficking to neuronal processes by its interaction with RBPs or by its direct binding to mRNA 3'-UTRs (Table 1).

\section{Parkinson's Disease (PD)}

Parkinson's disease is a chronic neurodegenerative disorder in which dopaminergic neurons of the substantia nigra progressively die and there is an accumulation of Lewy bodies composed of abnormal intracellular aggregates of alpha synuclein protein ( $\alpha$ Syn) and ubiquitin (Goedert et al., 2013). The 
pathogenic process in PD involves regions of the central and peripheral NS with bradykinesia, rigidity and other motor symptoms being the main clinical manifestations (Halliday and McCann, 2010). As in AD, pathological signs at cellular levels appear before clinical symptoms and lead to the loss of $60-70 \%$ of neurons in the substantia nigra pars compacta (Radhakrishnan and Goyal, 2018).

Impairment of local protein synthesis in PD has not been fully demonstrated. However, a recent review by Lin and colleagues commented on this possibility. Given their complex morphology, neurons cope with stress in a compartmentalized manner (Lin et al., 2020). In PD, as in AD, prion disease and other disorders in which protein aggregation occurs, stress responses in neurons are evident before the pathological hallmarks of the disease are apparent. Oxidative stress and ER stress induce mechanisms able to cope with basal levels of neuronal damage. However, when a certain threshold is reached, those same mechanisms might backfire and contribute to neurodegeneration. Interestingly, the dual role and compartmentalized nature of stress mechanisms was implicitly reported in a mouse model of acute amyloid pathology where locally translated ATF4 mediates neurodegeneration while global increases of this same transcription factor allows neurons to adapt to $A \beta$-induced stress (Baleriola et al., 2014). ATF4 is an important component of the unfolded protein response (UPR). The UPR involves a global shutdown of protein synthesis via eIf $2 \alpha$ while promoting translation of mRNAs encoding stress-related proteins. ATF4 is classically synthesized upon accumulation of unfolded and misfolded proteins and the consequent UPR activation due to ER stress. However, in A $\beta$-treated axons, ATF4 translation (likely via eIf $2 \alpha$ ) but no other canonical signs of the UPR, such as protein synthesis shutdown, are apparent. A partial, non-canonical activation of the UPR has also been observed in developing axons when challenged with Sema3a (Cagnetta et al., 2019). The UPR is known to be altered in $\mathrm{AD}, \mathrm{PD}$ with Lewy bodies, prion disease, $\mathrm{HD}$ and even ALS (Hetz and Saxena, 2017). It would be interesting to address if in neurodegenerative diseases other than $\mathrm{AD}$, such as $\mathrm{PD}$, a compartment-dependent UPR involving local translation contributes to disease progression (Figure 4A).

On the other hand, several studies implicate translation in PD pathogenesis. Proteins encoded by PD-associated genes have recently been shown to interact with components of the translation initiation complex. For instance, Leucine-rich repeat kinase 2 (LRRK2) whose mutations are involved in autosomal dominant Parkinson's disease, phosphorylates 4E-BP, releasing the repression from the initiation factors eIF4E/eIF4G. Mutant forms of LRRK2 in Drosophila stimulate eIF4E inducing aberrantly high protein synthesis accompanied by loss of dopaminergic neurons (Imai et al., 2008). LRRK2 is also known to regulate eIF4E/4E-BP in mammals but results seem to be conflicting. Whereas in vitro experiments indicate increased $4 \mathrm{E}-$ BP phosphorylation induced by LRRK2 (Kumar et al., 2010), Trancikova and colleagues did not observe any effect on 4E-BP with in vivo gain- or loss-of-function approaches (Trancikova et al., 2012). Others, however, have observed increased phospho4E-BP levels in LRRK2 KO and LRRK2 kinase dead but not in knock-in transgenic mice (Herzig et al., 2011). The so far inconclusive results on the effect of LRRK2 on the eIF4E/4E-BP axis might be due to the analyses being performed in whole cells and tissues. It would be interesting to determine whether in PD, as in $\mathrm{A} \beta$ pathology, $4 \mathrm{E}-\mathrm{BP}$ dependent translation is enhanced in axons (Baleriola et al., 2014).

Work from Gehrke and colleagues suggested that translation repression induced by pathogenic LRRK2 is elicited through repression of miRNAs. Interestingly, miRNAs can be found in axons (Natera-Naranjo et al., 2010) and as mentioned before miR-183 regulates axonally synthesized mTOR which in turn modulates local protein synthesis in SMA (Kye et al., 2014). It would be worth determining if a similar local mechanism is involved in the pathogenesis of PD (see *PD in Figure 3B).

Mutations in Pten-induced kinase 1 (PINK1/PARK6) or Parkin (PARK2), which are involved in early-onset autosomal recessive PD alter mitochondrial function. PINK1 and PARK2 promote mitochondrial localization and translation of specific mRNAs at the mitochondrial outer membrane (Gehrke et al., 2015). Translation activation via PINK1 and PARK2 implies the displacement of the repressive RBPs Pumilio and Glorund/hnRNP-F (Mouton-Liger et al., 2017). Both proteins influence mitochondrial function and play an important role in translation. Whether both RBPs play a role in localized translation in PD remains unknown. Interestingly, however, Pumilio 2 is known to regulate the local transcriptome of developing axons (Martinez et al., 2019) (*PD in Figure 5C).

Although there are so far no concluding remarks on how local translation could contribute to PD pathogenesis, the fact that global protein synthesis is likely aberrantly high and that there are similarities with $\mathrm{AD}$ and $\mathrm{HD}$ strongly point to the possibility that RNA localization and localized translation in neurons are compromised in this disease and might even contribute to its progression.

\section{Autism Spectrum Disorders (ASD) and Fragile X Syndrome (FXS)}

Autism spectrum disorders is a term referred to heterogeneous behavioral disorders with a combination of difficulties in different areas including intellectual, communication or social interaction. The most common monogenic cause of ASD is FXS, a neurodevelopmental disorder which causes intellectual disability attributed to FMRP protein deficiency as a result of a mutation in the FMR1 gene (Salcedo-Arellano et al., 2020). One of the main cell-pathological features of FXS is the high levels of dendritic spines with an abnormal morphology linked to delayed maturation (Banerjee et al., 2018).

Fragile X mental retardation protein is a well-known RBP whose implication in dendritic local translation has been widely studied. FMRP is involved in several steps of local protein synthesis: from mRNA trafficking to peripheral processes to ribosome stalling or microRNA regulation. In relation to mRNA transport, Feuge et al. (2019) described that FMRP binds to Cof 1 mRNA and regulates its localization to and translation within dendrites. Cof 1 encodes cofilin 1, an actin-binding protein involved in dendritic spine structure and plasticity, and it was 
recently associated with the FXS pathology (Pyronneau et al., 2017). In Fmr1 KO mice, defects on local Cof1 mRNA were observed with the consequent plasticity impairment (Feuge et al., 2019). Additionally, FMRP target mRNAs encoding synaptic proteins have also been reported, including $A r c, C a m k 2 a, D l g 4$, or Map1b. Interestingly, Frm $1 \mathrm{mRNA}$ itself is localized to dendrites (Antar et al., 2004; Banerjee et al., 2018). Hence, the loss of FMRP leads to mislocalization and altered local translation of FMRP binding mRNAs, and FMRP deficiency is likely linked to defects in spine morphology and in neuronal plasticity observed in FXS.

Besides interacting with target mRNAs, FMRP can also bind reversibly to ribosomes and paralyzes the elongation phase of translation (Feng et al., 1997; Darnell et al., 2011; Chen et al., 2014). Furthermore, deregulated miRNAs were observed in postmortem brain tissue from ASD patients (Abu-Elneel et al., 2008). Interestingly, PSD-95 (encoded by Dlg4) local synthesis in dendritic compartments is mediated by the also dendritically localized miR-125a in FXS. FMRP is required for miR-125a activity through the RNA-induced silencing complex (RISC). Indeed, in Fmr1 KO neurons Dlg4 translation is increased while miR-125a levels are reduced in Fmrl KO synaptoneurosomes, affecting spine morphology and branching (Muddashetty et al., 2011).

Fragile X mental retardation protein binds ALS/FTD-linked TDP-43 to regulate the transport of mRNP granules in mouse dendrites. The association between FMRP and TDP-43 RBPs in mRNPs trafficking again opens new venues to shed light on common pathophysiological mechanisms of mRNA localization and localized translation underlying neurodevelopmental and neurodegenerative diseases (Chu et al., 2019).

Despite most evidence links FMRP to local translation in dendrites, FMRP-containing RNP granules have been detected in developing and mature axons as well (Christie et al., 2009; Akins et al., 2012, 2017). Additionally, axonal Map1b and Calm1 mRNAs have been identified as miR-181d targets. FMRP appears to associate with miR-181d and its target mRNAs in dorsal root ganglion neurons (DRGs) upon nerve growth factor (NGF) stimulation and regulates axon outgrowth. FMRP deficiency in vitro and in a FXS mouse model leads to the mislocalization of miR-181d, Map1b and Calm1 (Wang et al., 2015). Further research is required on this regard to clarify the involvement of FMRP in intra-axonal protein synthesis and the more than likely contribution thereof to FXS pathology.

Finally, FMRP is able to regulate mTOR activity in dendrites. mTOR is not only considered a regulator of axonal translation but it is also involved in intra-dendritic protein synthesis. In Fmr1 KO mice and in studies of FXS patients, an upregulation of mTOR was detected. In addition, mTOR is also altered in other FMRPdeficiency diseases, such as tuberous sclerosis, Rett syndrome, and Down syndrome (Hagerman et al., 2010; Wang et al., 2010; Troca-Marin et al., 2011).

From all the documented evidence gathered in this section it seems clear that FXS is one of the best examples of the extent to which deregulation of local mRNA translation contributes to disease progression. The abnormal morphology of dendritic spines typically observed in FXS could be explained by the wide involvement of FMRP in dendritic local protein synthesis. As summarized in Table 1, FMRP defects entail deregulation of dendritically localized mRNAs and miRNAs, which results in spine morphology and plasticity impairment. Furthermore, dendritic mTOR is also controlled by FMRP. All this knowledge will allow a better understanding of ASD and will hopefully help develop new therapeutic strategies (Figure 5A).

\section{Down Syndrome (DS)}

Down syndrome is the most common genetic cause of intellectual disability triggered by trisomy of human chromosome 21 . Neurological symptoms are accompanied by abnormal physical growth. In some DS cases congenital heart defects are apparent. Duodenal stenosis or leukemia are also more frequent in DS patients than in the general population (Antonarakis et al., 2004). Although the specific mechanisms leading to neurological signs remain poorly understood, it is known that DS is characterized by defects in dendrite morphology and synaptic plasticity similarly to other developmental diseases like FXS (Alves-Sampaio et al., 2010). The mRNA encoding the DS cell adhesion molecule (DSCAM) is present in dendrites and DSCAM has been suggested to play a role in synaptic plasticity. Therefore, altered Dscam mRNA localization and defects in DSCAM local synthesis might contribute to DS-related pathogenic features in neurons. In fact, Dscam mRNA levels as well as its localized translation are increased within dendrites of hippocampal neurons leading to a negative effect on dendrite branching in a DS mouse model (Alves-Sampaio et al., 2010). Additionally, the same DS model presents increased dendritic levels of BDNF, which is a local protein synthesis modulator (Swanger and Bassell, 2013). Consequently, the rate of local translation in dendrites is aberrantly increased (Troca-Marin et al., 2011; Figure 5B).

\section{Other Neurological Disorders}

Interestingly, a point mutation in the human $B D N F$ gene is associated with depression and bipolar disorder. The presence of the human BDNF mutation in a mouse model disrupts the localization of Bdnf mRNA to dendrites (Swanger and Bassell, 2013). These data suggest that altered Bdnf localization and the consequent defects in its translation might contribute to psychiatric disorders (Figure 5B), although this contribution should be explored further.

Finally, epilepsy is also associated with deficiencies in RBPs. For instance, in 2017 Pumilio-2 was described as an RBP involved in epileptogenesis (Follwaczny et al., 2017). A recent study has described Pumilio- 2 as a regulator of the axonal transcriptome in developing axons, whose mechanism of action is the exclusion of RNAs from the axonal compartment by retaining them in the cell body. Importantly, Pumilio-2 knockdown not only leads to the erroneous axonal mRNAs localization and increased overall translation levels in axons, but also to branching defects (Martinez et al., 2019) as summarized in Figure 5C.

To sum up, increasing evidence suggest that mRNA localization and local protein synthesis might be a key contributor to NS pathological conditions, not only in neurodegenerative diseases but also in other neurological disorders as discussed in these paragraphs. 


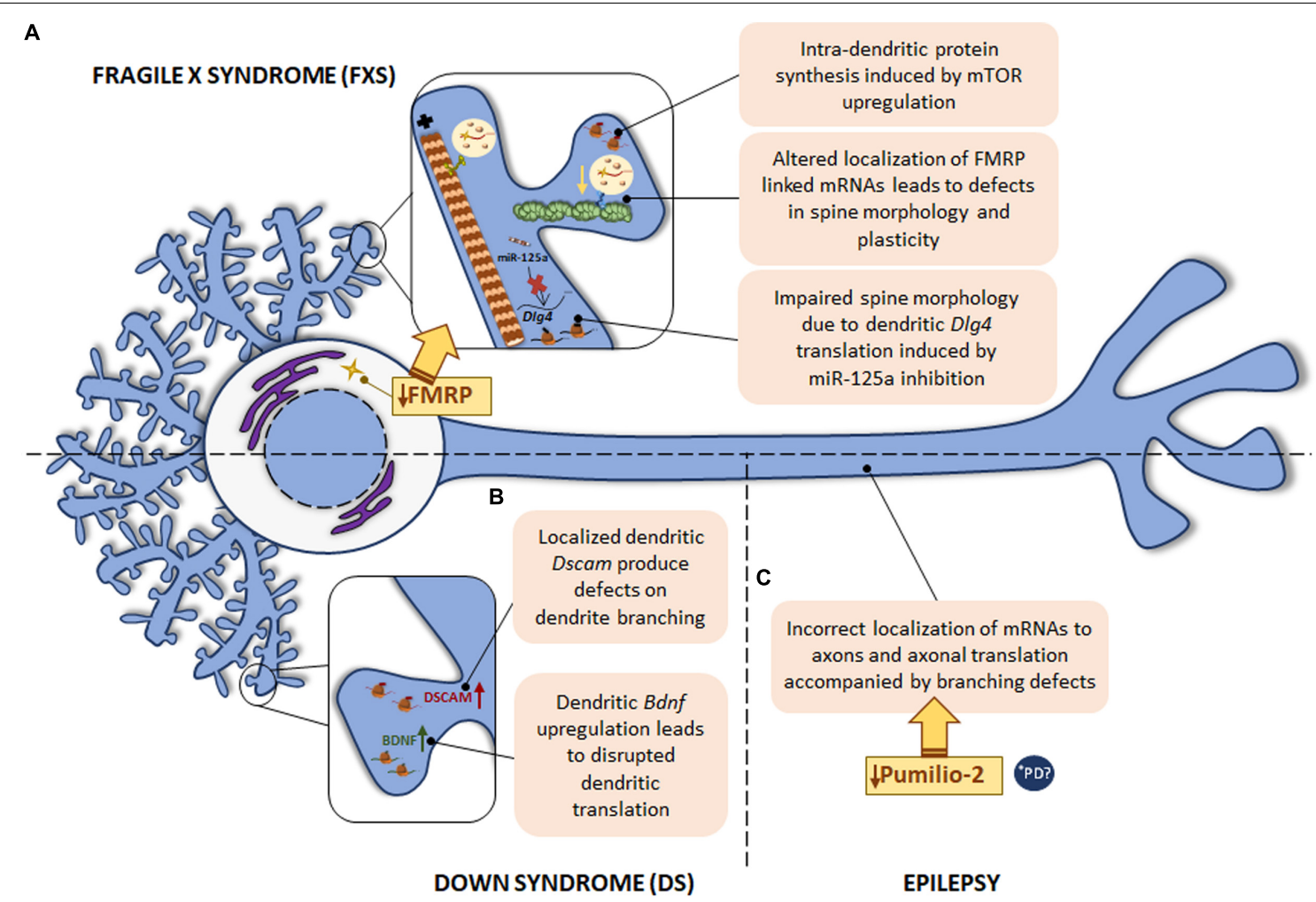

FIGURE 5 | Local translation defects in FXS, DS and epilepsy. (A) The most common monogenic cause of ASD is FXS, caused by a mutation in FMR1 gene with the consequent FMRP protein deficiency. FMRP regulates RNA metabolism at different levels and therefore, intra-dendritic translation is altered at several points: mTOR-mediated local protein synthesis is upregulated; deregulation of local mRNAs-linked to FMRP leads to abnormal spine morphology and plasticity; deregulation of miR-125a induces Dlg4 mRNA dendritic translation with spine morphology defects. (B) DS, caused by trisomy of chromosome 21 , is characterized by defects in dendrite morphology, which can be due to the increased levels of Dscam and Bdnf mRNAs in dendrites. The localization of Bdnf to dendrites is also disrupted in psychiatric disorders. (C) In epilepsy, deficiency in the RBP Pumilio-2 results in incorrect localization of mRNAs to axons and increased overall intra-axonal translation with the consequent branching defects. *PD PINK1 and PARK2, involved in PD pathogenesis, regulate translation of mitochondrial proteins by displacement of Pumilio-2 and other RBPs. Due to the local role of Pumilio-2 in translation in developing axons, localized translation in PD could also be altered.

\section{CONCLUDING REMARKS}

The data reviewed in this article bring to light the increasing body of evidence on the relevance of mRNA localization and local protein synthesis not only in brain development and physiology but also in NS pathologies including neurodegenerative diseases (Table 1). We cannot, however, overlook the limitations in studying local protein synthesis. While we can separate different subneuronal compartments in vitro using diverse specialized culture systems (microfluidic chambers, modified Boyden chambers...), this task cannot be performed in vivo. In whole animals, neuronal processes are intermingled and cannot be found in isolation. Even when synaptosomes can be isolated from entire tissues, thorough controls have to be performed in order to ensure that RNAs and proteins of interest are indeed localized to neuronal peripheral domains and/or are a result of local protein synthesis. Additionally, often times the amount of material obtained from synaptosomes or brain regions enriched in neurites (e.g., the neuropil) is limiting. Identification of specific transcripts and proteins along neuronal processes is possible also by in situ hybridization and immunohistochemical approaches, which can also be performed in human brain tissue and thereby, this kind of samples contribute to clarify the findings in culture and animal brains, supporting the significance of localized mRNAs and the translation machinery in several pathophysiological contexts. However, postmortem tissue does not allow mechanistic assessment and cell-compartment isolation from brain neurons is not possible at clinical stages. Human studies are thus one of the main challenges in the field of local protein synthesis.

On the other hand, localized translation research in the context of pathologies provides new exciting venues for the development of novel therapeutic targets for nervous system pathologies although localized strategies should be explored more in detail. For instance, current technologies do not allow the knockdown of specific axonal mRNAs without altering the somatic counterparts. Every effort should be done to develop new approaches on this matter. Nevertheless, it is worth noting that local protein synthesis in neurons does not seem to rely only on the neurons but that glial cells might contribute to this phenomenon. Interestingly, in the peripheral nervous system, Schwann cells transfer ribosomes to injured sciatic nerves 
(Court et al., 2008) whereas in the spinal cord, a transference of ribosome-like particles at the axonal-myelin sheath interface has suggested (Li et al., 2005). These data point at the possibility of a novel therapeutic strategy based on modulating glia-neuron transference instead of interfering directly with translation at subneuronal compartments. In either case, further research is still required.

\section{AUTHOR CONTRIBUTIONS}

JB conceived the work. MG, $\mathrm{AC}$, and $\mathrm{MB}-\mathrm{U}$ drafted the manuscript. MG, AC, and JB composed figures and tables. MG,

\section{REFERENCES}

Abu-Elneel, K., Liu, T., Gazzaniga, F. S., Nishimura, Y., Wall, D. P., Geschwind, D. H., et al. (2008). Heterogeneous dysregulation of microRNAs across the autism spectrum. Neurogenetics 9, 153-161. doi: 10.1007/s10048-0080133-5

Akins, M. R., Berk-Rauch, H. E., Kwan, K. Y., Mitchell, M. E., Shepard, K. A., Korsak, L. I., et al. (2017). Axonal ribosomes and mRNAs associate with fragile X granules in adult rodent and human brains. Hum Mol Genet 26, 192-209. doi: 10.1093/hmg/ddw381

Akins, M. R., Leblanc, H. F., Stackpole, E. E., Chyung, E., and Fallon, J. R. (2012). Systematic mapping of fragile X granules in the mouse brain reveals a potential role for presynaptic FMRP in sensorimotor functions. J Comp Neurol 520, 3687-3706. doi: 10.1002/cne.23123

Akiyama, T., Suzuki, N., Ishikawa, M., Fujimori, K., Sone, T., Kawada, J., et al. (2019). Aberrant axon branching via Fos-B dysregulation in FUS-ALS motor neurons. EBioMedicine 45, 362-378. doi: 10.1016/j.ebiom.2019.06.013

Alami, N. H., Smith, R. B., Carrasco, M. A., Williams, L. A., Winborn, C. S., Han, S. S. W., et al. (2014). Axonal transport of TDP-43 mRNA granules is impaired by ALS-causing mutations. Neuron 81, 536-543. doi: 10.1016/j.neuron.2013.12. 018

Alberts, B., Johnson, A., Lewis, J., Raff, M., Roberts, K., and Walter, P. (2002). Molecular Biology of the Cell, 4th Edn. New York, NY: Garland Science.

Alves-Sampaio, A., Troca-Marin, J. A., and Montesinos, M. L. (2010). NMDAmediated regulation of DSCAM dendritic local translation is lost in a mouse model of Down's syndrome. J Neurosci 30, 13537-13548. doi: 10.1523/ JNEUROSCI.3457-10.2010

Antar, L. N., Afroz, R., Dictenberg, J. B., Carroll, R. C., and Bassell, G. J. (2004). Metabotropic glutamate receptor activation regulates fragile $\mathrm{x}$ mental retardation protein and FMR1 mRNA localization differentially in dendrites and at synapses. J Neurosci 24, 2648-2655. doi: 10.1523/JNEUROSCI.0099-04. 2004

Antonarakis, S. E., Lyle, R., Dermitzakis, E. T., Reymond, A., and Deutsch, S. (2004). Chromosome 21 and down syndrome: from genomics to pathophysiology. Nat Rev Genet 5, 725-738. doi: 10.1038/nrg1448

Aronov, S., Aranda, G., Behar, L., and Ginzburg, I. (2001). Axonal tau mRNA localization coincides with tau protein in living neuronal cells and depends on axonal targeting signal. J Neurosci 21, 6577-6587.

Baleriola, J., and Hengst, U. (2015). Targeting axonal protein synthesis in neuroregeneration and degeneration. Neurotherapeutics 12, 57-65. doi: 10. 1007/s13311-014-0308-8

Baleriola, J., Walker, C. A., Jean, Y. Y., Crary, J. F., Troy, C. M., Nagy, P. L., et al. (2014). Axonally synthesized ATF4 transmits a neurodegenerative signal across brain regions. Cell 158, 1159-1172. doi: 10.1016/j.cell.2014.07.001

Banerjee, A., Ifrim, M. F., Valdez, A. N., Raj, N., and Bassell, G. J. (2018). Aberrant RNA translation in fragile X syndrome: From FMRP mechanisms to emerging therapeutic strategies. Brain Res 1693(Pt A), 24-36. doi: 10.1016/j.brainres. 2018.04.008

Bannister, N. J., and Larkman, A. U. (1995). Dendritic morphology of CA1 pyramidal neurones from the rat hippocampus: II. Spine distributions. J Comp Neurol 360, 161-171. doi: 10.1002/cne.903600112
AC, MB- $\mathrm{U}$, and JB performed literature searching and edited the manuscript. All authors contributed to the article and approved the submitted version.

\section{FUNDING}

This work was partially funded by grants awarded to JB (MICINN grants SAF2016-76347-R, RYC-2016-19837, and PID2019-110721RB-I00; The Alzheimer's Association grants AARG-19-618303 and AARG-19-618303-RAPID). MG and AC are GV fellows; MB-U is a UPV/EHU fellow.

Bassell, G. J., Zhang, H., Byrd, A. L., Femino, A. M., Singer, R. H., Taneja, K. L., et al. (1998). Sorting of beta-actin mRNA and protein to neurites and growth cones in culture. J Neurosci 18, 251-265.

Batista, A. F. R., Martinez, J. C., and Hengst, U. (2017). Intra-axonal Synthesis of SNAP25 Is Required for the Formation of Presynaptic Terminals. Cell Rep 20, 3085-3098. doi: 10.1016/j.celrep.2017.08.097

Baumann, S., Konig, J., Koepke, J., and Feldbrugge, M. (2014). Endosomal transport of septin mRNA and protein indicates local translation on endosomes and is required for correct septin filamentation. EMBO Rep 15, 94-102. doi: 10.1002/embr.201338037

Ben-Yaakov, K., Dagan, S. Y., Segal-Ruder, Y., Shalem, O., Vuppalanchi, D., Willis, D. E., et al. (2012). Axonal transcription factors signal retrogradely in lesioned peripheral nerve. EMBO J 31, 1350-1363. doi: 10.1038/emboj. 2011.494

Berkovits, B. D., and Mayr, C. (2015). Alternative $3^{\prime}$ UTRs act as scaffolds to regulate membrane protein localization. Nature 522, 363-367. doi: 10.1038/ nature 14321

Berson, A., Barbash, S., Shaltiel, G., Goll, Y., Hanin, G., Greenberg, D. S., et al. (2012). Cholinergic-associated loss of hnRNP-A/B in Alzheimer's disease impairs cortical splicing and cognitive function in mice. EMBO Mol Med 4, 730-742. doi: 10.1002/emmm.201100995

Biever, A., Glock, C., Tushev, G., Ciirdaeva, E., Dalmay, T., Langer, J. D., et al. (2020). Monosomes actively translate synaptic mRNAs in neuronal processes. Science 367, eaay4991. doi: 10.1126/science.aay4991

Blanco-Urrejola, M., Gaminde-Blasco, A., Gamarra, M., de la Cruz, A., Vecino, E., Alberdi, E., et al. (2021). RNA Localization and Local Translation in Glia in Neurological and Neurodegenerative Diseases: Lessons from Neurons. Cells 10, 632.

Bosco, D. A., Lemay, N., Ko, H. K., Zhou, H., Burke, C., Kwiatkowski, T. J. Jr., et al. (2010). Mutant FUS proteins that cause amyotrophic lateral sclerosis incorporate into stress granules. Hum Mol Genet 19, 4160-4175. doi: 10.1093/ hmg/ddq335

Bott, N. T., Radke, A., Stephens, M. L., and Kramer, J. H. (2014). Frontotemporal dementia: diagnosis, deficits and management. Neurodegener Dis Manag 4, 439-454. doi: 10.2217/nmt.14.34

Burgin, K. E., Waxham, M. N., Rickling, S., Westgate, S. A., Mobley, W. C., and Kelly, P. T. (1990). In situ hybridization histochemistry of Ca2+/calmodulindependent protein kinase in developing rat brain. J Neurosci 10, 1788-1798.

Burguete, A. S., Almeida, S., Gao, F. B., Kalb, R., Akins, M. R., and Bonini, N. M. (2015). GGGGCC microsatellite RNA is neuritically localized, induces branching defects, and perturbs transport granule function. Elife 4, e08881. doi: 10.7554/eLife.08881

Busche, M. A., and Hyman, B. T. (2020). Synergy between amyloid-beta and tau in Alzheimer's disease. Nat Neurosci 23, 1183-1193. doi: 10.1038/s41593-0200687-6

Cagnetta, R., Wong, H. H., Frese, C. K., Mallucci, G. R., Krijgsveld, J., and Holt, C. E. (2019). Noncanonical Modulation of the eIF2 Pathway Controls an Increase in Local Translation during Neural Wiring. Mol Cell 73, 474.e-489.e. doi: 10.1016/j.molcel.2018.11.013 
Chen, E., Sharma, M. R., Shi, X., Agrawal, R. K., and Joseph, S. (2014). Fragile $\mathrm{X}$ mental retardation protein regulates translation by binding directly to the ribosome. Mol Cell 54, 407-417. doi: 10.1016/j.molcel.2014.03.023

Christie, S. B., Akins, M. R., Schwob, J. E., and Fallon, J. R. (2009). The FXG: a presynaptic fragile $\mathrm{X}$ granule expressed in a subset of developing brain circuits. J Neurosci 29, 1514-1524. doi: 10.1523/JNEUROSCI.3937-08.2009

Chu, J. F., Majumder, P., Chatterjee, B., Huang, S. L., and Shen, C. J. (2019). TDP-43 Regulates Coupled Dendritic mRNA Transport-Translation Processes in Co-operation with FMRP and Staufen1. Cell Rep 29, 3118.e-3133.e. doi: 10.1016/j.celrep.2019.10.061

Cioni, J. M., Lin, J. Q., Holtermann, A. V., Koppers, M., Jakobs, M. A. H., Azizi, A., et al. (2019). Late Endosomes Act as mRNA Translation Platforms and Sustain Mitochondria in Axons. Cell 176, 56.e-72.e. doi: 10.1016/j.cell.2018.11.030

Court, F. A., Hendriks, W. T., MacGillavry, H. D., Alvarez, J., and van Minnen, J. (2008). Schwann cell to axon transfer of ribosomes: toward a novel understanding of the role of glia in the nervous system. J Neurosci 28, 1102411029. doi: 10.1523/JNEUROSCI.2429-08.2008

Coyne, A. N., Siddegowda, B. B., Estes, P. S., Johannesmeyer, J., Kovalik, T., Daniel, S. G., et al. (2014). Futsch/MAP1B mRNA is a translational target of TDP-43 and is neuroprotective in a Drosophila model of amyotrophic lateral sclerosis. J Neurosci 34, 15962-15974. doi: 10.1523/JNEUROSCI.2526-14. 2014

Craig, E. M. (2018). Model for Coordination of Microtubule and Actin Dynamics in Growth Cone Turning. Front Cell Neurosci 12:394. doi: 10.3389/fncel.2018. 00394

Darnell, J. C., Van Driesche, S. J., Zhang, C., Hung, K. Y., Mele, A., Fraser, C. E., et al. (2011). FMRP stalls ribosomal translocation on mRNAs linked to synaptic function and autism. Cell 146, 247-261. doi: 10.1016/j.cell.2011.06. 013

Dixit, R., Ross, J. L., Goldman, Y. E., and Holzbaur, E. L. (2008). Differential regulation of dynein and kinesin motor proteins by tau. Science 319, 1086-1089. doi: $10.1126 /$ science. 1152993

Edstrom, A., and Sjostrand, J. (1969). Protein synthesis in the isolated Mauthner nerve fibre of goldfish. J Neurochem 16, 67-81. doi: 10.1111/j.1471-4159.1969. tb10344.x

Endo, R., Takashima, N., Nekooki-Machida, Y., Komi, Y., Hui, K. K., Takao, M., et al. (2018). TAR DNA-Binding Protein 43 and Disrupted in Schizophrenia 1 Coaggregation Disrupts Dendritic Local Translation and Mental Function in Frontotemporal Lobar Degeneration. Biol Psychiatry 84, 509-521. doi: 10.1016/ j.biopsych.2018.03.008

Fallini, C., Donlin-Asp, P. G., Rouanet, J. P., Bassell, G. J., and Rossoll, W. (2016). Deficiency of the Survival of Motor Neuron Protein Impairs mRNA Localization and Local Translation in the Growth Cone of Motor Neurons. J Neurosci 36, 3811-3820. doi: 10.1523/JNEUROSCI.2396-15. 2016

Fallini, C., Rouanet, J. P., Donlin-Asp, P. G., Guo, P., Zhang, H., Singer, R. H., et al. (2014). Dynamics of survival of motor neuron (SMN) protein interaction with the mRNA-binding protein IMP1 facilitates its trafficking into motor neuron axons. Dev Neurobiol 74, 319-332. doi: 10.1002/dneu.22111

Fallini, C., Zhang, H., Su, Y., Silani, V., Singer, R. H., Rossoll, W., et al. (2011). The survival of motor neuron (SMN) protein interacts with the mRNA-binding protein $\mathrm{HuD}$ and regulates localization of poly(A) mRNA in primary motor neuron axons. J Neurosci 31, 3914-3925. doi: 10.1523/JNEUROSCI.3631-10. 2011

Feng, Y., Absher, D., Eberhart, D. E., Brown, V., Malter, H. E., and Warren, S. T. (1997). FMRP associates with polyribosomes as an mRNP, and the I304N mutation of severe fragile X syndrome abolishes this association. Mol Cell 1, 109-118. doi: 10.1016/s1097-2765(00)80012-x

Feuge, J., Scharkowski, F., Michaelsen-Preusse, K., and Korte, M. (2019). FMRP Modulates Activity-Dependent Spine Plasticity by Binding Cofilin 1 mRNA and Regulating Localization and Local Translation. Cereb Cortex 29, 5204-5216. doi: $10.1093 /$ cercor/bhz059

Follwaczny, P., Schieweck, R., Riedemann, T., Demleitner, A., Straub, T., Klemm, A. H., et al. (2017). Pumilio2-deficient mice show a predisposition for epilepsy. Dis Model Mech 10, 1333-1342. doi: 10.1242/dmm.029678

Formicola, N., Vijayakumar, J., and Besse, F. (2019). Neuronal ribonucleoprotein granules: Dynamic sensors of localized signals. Traffic 20, 639-649. doi: 10. $1111 /$ tra. 12672
Fratta, P., Mizielinska, S., Nicoll, A. J., Zloh, M., Fisher, E. M., Parkinson, G., et al. (2012). C9orf72 hexanucleotide repeat associated with amyotrophic lateral sclerosis and frontotemporal dementia forms RNA G-quadruplexes. Sci Rep 2, 1016. doi: 10.1038/srep01016

Gamarra, M., Blanco-Urrejola, M., Batista, A. F. R., Imaz, J., and Baleriola, J. (2020). Object-Based Analyses in FIJI/ImageJ to Measure Local RNA Translation Sites in Neurites in Response to Abeta1-42 Oligomers. Front Neurosci 14:547. doi: 10.3389/fnins.2020.00547

Garner, C. C., and Matus, A. (1988). Different forms of microtubule-associated protein 2 are encoded by separate mRNA transcripts. J Cell Biol 106, 779-783. doi: $10.1083 /$ jcb.106.3.779

Gauthier, L. R., Charrin, B. C., Borrell-Pages, M., Dompierre, J. P., Rangone, H., Cordelieres, F. P., et al. (2004). Huntingtin controls neurotrophic support and survival of neurons by enhancing BDNF vesicular transport along microtubules. Cell 118, 127-138. doi: 10.1016/j.cell.2004.06.018

Gauthier-Kemper, A., Suarez Alonso, M., Sundermann, F., Niewidok, B., Fernandez, M. P., Bakota, L., et al. (2018). Annexins A2 and A6 interact with the extreme $\mathrm{N}$ terminus of tau and thereby contribute to tau's axonal localization. $J$ Biol Chem 293, 8065-8076. doi: 10.1074/jbc.RA117.000490

Gehrke, S., Wu, Z., Klinkenberg, M., Sun, Y., Auburger, G., Guo, S., et al. (2015). PINK1 and Parkin control localized translation of respiratory chain component mRNAs on mitochondria outer membrane. Cell Metab 21, 95-108. doi: 10.1016/ j.cmet.2014.12.007

Giuditta, A., Dettbarn, W. D., and Brzin, M. (1968). Protein synthesis in the isolated giant axon of the squid. Proc Natl Acad Sci U S A 59, 1284-1287. doi: 10.1073/pnas.59.4.1284

Goedert, M., Ghetti, B., and Spillantini, M. G. (2012). Frontotemporal dementia: implications for understanding Alzheimer disease. Cold Spring Harb Perspect Med 2, a006254. doi: 10.1101/cshperspect.a006254

Goedert, M., Spillantini, M. G., Del Tredici, K., and Braak, H. (2013). 100 years of Lewy pathology. Nat Rev Neurol 9, 13-24. doi: 10.1038/nrneurol.2012.242

Groen, E. J., Fumoto, K., Blokhuis, A. M., Engelen-Lee, J., Zhou, Y., van den Heuvel, D. M., et al. (2013). ALS-associated mutations in FUS disrupt the axonal distribution and function of SMN. Hum Mol Genet 22, 3690-3704. doi: $10.1093 / \mathrm{hmg} / \mathrm{ddt} 222$

Gu, J., Wu, F., Xu, W., Shi, J., Hu, W., Jin, N., et al. (2017). TDP-43 suppresses tau expression via promoting its mRNA instability. Nucleic Acids Res 45, 6177-6193. doi: 10.1093/nar/gkx175

Guillaud, L., El-Agamy, S. E., Otsuki, M., and Terenzio, M. (2020). Anterograde Axonal Transport in Neuronal Homeostasis and Disease. Front Mol Neurosci 13:556175. doi: 10.3389/fnmol.2020.556175

Hagerman, R., Hoem, G., and Hagerman, P. (2010). Fragile X and autism: Intertwined at the molecular level leading to targeted treatments. Mol Autism 1, 12. doi: 10.1186/2040-2392-1-12

Halliday, G. M., and McCann, H. (2010). The progression of pathology in Parkinson's disease. Ann N Y Acad Sci 1184, 188-195. doi: 10.1111/j.1749-6632. 2009.05118.x

Hanz, S., Perlson, E., Willis, D., Zheng, J. Q., Massarwa, R., Huerta, J. J., et al. (2003). Axoplasmic importins enable retrograde injury signaling in lesioned nerve. Neuron 40, 1095-1104. doi: 10.1016/s0896-6273(03)00770-0

Hengst, U., Deglincerti, A., Kim, H. J., Jeon, N. L., and Jaffrey, S. R. (2009). Axonal elongation triggered by stimulus-induced local translation of a polarity complex protein. Nat Cell Biol 11, 1024-1030. doi: 10.1038/ncb1916

Herzig, M. C., Kolly, C., Persohn, E., Theil, D., Schweizer, T., Hafner, T., et al. (2011). LRRK2 protein levels are determined by kinase function and are crucial for kidney and lung homeostasis in mice. Hum Mol Genet 20, 4209-4223. doi: $10.1093 / \mathrm{hmg} / \mathrm{ddr} 348$

Hetz, C., and Saxena, S. (2017). ER stress and the unfolded protein response in neurodegeneration. Nat Rev Neurol 13, 477-491. doi: 10.1038/nrneurol.2017.99

Hirokawa, N., Niwa, S., and Tanaka, Y. (2010). Molecular motors in neurons: transport mechanisms and roles in brain function, development, and disease. Neuron 68, 610-638. doi: 10.1016/j.neuron.2010.09.039

Hoek, K. S., Kidd, G. J., Carson, J. H., and Smith, R. (1998). hnRNP A2 selectively binds the cytoplasmic transport sequence of myelin basic protein mRNA. Biochemistry 37, 7021-7029. doi: 10.1021/bi9800247

Holt, C. E., Martin, K. C., and Schuman, E. M. (2019). Local translation in neurons: visualization and function. Nat Struct Mol Biol 26, 557-566. doi: 10.1038/ s41594-019-0263-5 
Imai, Y., Gehrke, S., Wang, H. Q., Takahashi, R., Hasegawa, K., Oota, E., et al. (2008). Phosphorylation of $4 \mathrm{E}-\mathrm{BP}$ by LRRK2 affects the maintenance of dopaminergic neurons in Drosophila. EMBO J 27, 2432-2443. doi: 10.1038/ emboj. 2008.163

Khalil, B., Morderer, D., Price, P. L., Liu, F., and Rossoll, W. (2018). mRNP assembly, axonal transport, and local translation in neurodegenerative diseases. Brain Res 1693(Pt A), 75-91. doi: 10.1016/j.brainres.2018.02.018

Kim, H. K., Kim, Y. B., Kim, E. G., and Schuman, E. (2005). Measurement of dendritic mRNA transport using ribosomal markers. Biochem Biophys Res Commun 328, 895-900. doi: 10.1016/j.bbrc.2005.01.041

Kobayashi, S., Tanaka, T., Soeda, Y., Almeida, O. F. X., and Takashima, A. (2017). Local Somatodendritic Translation and Hyperphosphorylation of Tau Protein Triggered by AMPA and NMDA Receptor Stimulation. EBioMedicine 20, 120-126. doi: 10.1016/j.ebiom.2017.05.012

Koenig, E., and Koelle, G. B. (1960). Acetylcholinesterase regeneration in peripheral nerve after irreversible inactivation. Science 132, 1249-1250. doi: 10.1126/science.132.3435.1249

Kumar, A., Greggio, E., Beilina, A., Kaganovich, A., Chan, D., Taymans, J. M., et al. (2010). The Parkinson's disease associated LRRK2 exhibits weaker in vitro phosphorylation of $4 \mathrm{E}-\mathrm{BP}$ compared to autophosphorylation. PLoS One 5:e8730. doi: 10.1371/journal.pone.0008730

Kye, M. J., Niederst, E. D., Wertz, M. H., Goncalves Ido, C., Akten, B., Dover, K. Z., et al. (2014). SMN regulates axonal local translation via miR-183/mTOR pathway. Hum Mol Genet 23, 6318-6331. doi: 10.1093/hmg/ddu350

Landles, C., and Bates, G. P. (2004). Huntingtin and the molecular pathogenesis of Huntington's disease. Fourth in molecular medicine review series. EMBO Rep 5, 958-963. doi: 10.1038/sj.embor.7400250

Leal, G., Comprido, D., and Duarte, C. B. (2014). BDNF-induced local protein synthesis and synaptic plasticity. Neuropharmacology 76(Pt C), 639-656. doi: 10.1016/j.neuropharm.2013.04.005

Li, C., and Gotz, J. (2017). Somatodendritic accumulation of Tau in Alzheimer's disease is promoted by Fyn-mediated local protein translation. EMBO J 36, 3120-3138. doi: 10.15252/embj.201797724

Li, S. H., and Li, X. J. (2004). Huntingtin and its role in neuronal degeneration. Neuroscientist 10, 467-475. doi: 10.1177/1073858404266777

Li, Y. C., Li, Y. N., Cheng, C. X., Sakamoto, H., Kawate, T., Shimada, O., et al. (2005). Subsurface cisterna-lined axonal invaginations and double-walled vesicles at the axonal-myelin sheath interface. Neurosci Res 53, 298-303. doi: 10.1016/j.neures.2005.07.006

Liao, Y. C., Fernandopulle, M. S., Wang, G., Choi, H., Hao, L., Drerup, C. M., et al. (2019). RNA Granules Hitchhike on Lysosomes for Long-Distance Transport, Using Annexin A11 as a Molecular Tether. Cell 179, 147.e-164.e. doi: 10.1016/ j.cell.2019.08.050

Lin, J. Q., van Tartwijk, F. W., and Holt, C. E. (2020). Axonal mRNA translation in neurological disorders. RNA Biol 1-26. doi: 10.1080/15476286.2020.1822638

Ling, S. C., Albuquerque, C. P., Han, J. S., Lagier-Tourenne, C., Tokunaga, S., Zhou, H., et al. (2010). ALS-associated mutations in TDP-43 increase its stability and promote TDP-43 complexes with FUS/TLS. Proc Natl Acad Sci U S A 107, 13318-13323. doi: 10.1073/pnas.1008227107

Lopez-Erauskin, J., Tadokoro, T., Baughn, M. W., Myers, B., McAlonis-Downes, M., Chillon-Marinas, C., et al. (2018). ALS/FTD-Linked Mutation in FUS Suppresses Intra-axonal Protein Synthesis and Drives Disease Without Nuclear Loss-of-Function of FUS. Neuron 100, 816.e-830.e. doi: 10.1016/j.neuron.2018. 09.044

Ma, B., Culver, B. P., Baj, G., Tongiorgi, E., Chao, M. V., and Tanese, N. (2010). Localization of BDNF mRNA with the Huntington's disease protein in rat brain. Mol Neurodegener 5, 22. doi: 10.1186/1750-1326-5-22

Ma, B., Savas, J. N., Yu, M. S., Culver, B. P., Chao, M. V., and Tanese, N. (2011). Huntingtin mediates dendritic transport of beta-actin mRNA in rat neurons. Sci Rep 1, 140. doi: 10.1038/srep00140

Martin, K. C. (2004). Local protein synthesis during axon guidance and synaptic plasticity. Curr Opin Neurobiol 14, 305-310. doi: 10.1016/j.conb.2004. 05.009

Martinez, J. C., Randolph, L. K., Iascone, D. M., Pernice, H. F., Polleux, F., and Hengst, U. (2019). Pum2 Shapes the Transcriptome in Developing Axons through Retention of Target mRNAs in the Cell Body. Neuron 104, 931.e-946.e. doi: 10.1016/j.neuron.2019.08.035
Mouton-Liger, F., Jacoupy, M., Corvol, J. C., and Corti, O. (2017). PINK1/ParkinDependent Mitochondrial Surveillance: From Pleiotropy to Parkinson's Disease. Front Mol Neurosci 10:120. doi: 10.3389/fnmol.2017.00120

Muddashetty, R. S., Nalavadi, V. C., Gross, C., Yao, X., Xing, L., Laur, O., et al. (2011). Reversible inhibition of PSD-95 mRNA translation by miR-125a, FMRP phosphorylation, and mGluR signaling. Mol Cell 42, 673-688. doi: 10.1016/j. molcel.2011.05.006

Munro, T. P., Magee, R. J., Kidd, G. J., Carson, J. H., Barbarese, E., Smith, L. M., et al. (1999). Mutational analysis of a heterogeneous nuclear ribonucleoprotein A2 response element for RNA trafficking. J Biol Chem 274, 34389-34395. doi: $10.1074 /$ jbc. 274.48 .34389

Natera-Naranjo, O., Aschrafi, A., Gioio, A. E., and Kaplan, B. B. (2010). Identification and quantitative analyses of microRNAs located in the distal axons of sympathetic neurons. RNA 16, 1516-1529. doi: 10.1261/rna.183 3310

Pereiro, X., Ruzafa, N., Urcola, J. H., Sharma, S. C., and Vecino, E. (2020). Differential Distribution of RBPMS in Pig, Rat, and Human Retina after Damage. Int J Mol Sci 21, 9330. doi: 10.3390/ijms21239330

Perry, R. B., and Fainzilber, M. (2011). When zip codes are in short supply. EMBO J 30, 4520-4522. doi: 10.1038/emboj.2011.389

Piazzon, N., Rage, F., Schlotter, F., Moine, H., Branlant, C., and Massenet, S. (2008). In vitro and in cellulo evidences for association of the survival of motor neuron complex with the fragile X mental retardation protein. J Biol Chem 283, 5598-5610. doi: 10.1074/jbc.M707304200

Pushpalatha, K. V., and Besse, F. (2019). Local Translation in Axons: When Membraneless RNP Granules Meet Membrane-Bound Organelles. Front Mol Biosci 6:129. doi: 10.3389/fmolb.2019.00129

Pyronneau, A., He, Q., Hwang, J. Y., Porch, M., Contractor, A., and Zukin, R. S. (2017). Aberrant Rac1-cofilin signaling mediates defects in dendritic spines, synaptic function, and sensory perception in fragile X syndrome. Sci Signal 10, eaan0852. doi: 10.1126/scisignal.aan0852

Qamar, S., Wang, G., Randle, S. J., Ruggeri, F. S., Varela, J. A., Lin, J. Q., et al. (2018). FUS Phase Separation Is Modulated by a Molecular Chaperone and Methylation of Arginine Cation-pi Interactions. Cell 173, 720.e-734.e. doi: 10.1016/j.cell.2018.03.056

Rabbito, A., Dulewicz, M., Kulczynska-Przybik, A., and Mroczko, B. (2020). Biochemical Markers in Alzheimer's Disease. Int J Mol Sci 21, 1989. doi: 10. 3390/ijms21061989

Radhakrishnan, D. M., and Goyal, V. (2018). Parkinson's disease: A review. Neurol India 66(Suppl.), S26-S35. doi: 10.4103/0028-3886.226451

Rage, F., Boulisfane, N., Rihan, K., Neel, H., Gostan, T., Bertrand, E., et al. (2013). Genome-wide identification of mRNAs associated with the protein SMN whose depletion decreases their axonal localization. RNA 19, 1755-1766. doi: 10.1261/ rna.040204.113

Rangaraju, V., Calloway, N., and Ryan, T. A. (2014). Activity-driven local ATP synthesis is required for synaptic function. Cell 156, 825-835. doi: 10.1016/j. cell.2013.12.042

Rangaraju, V., Lauterbach, M., and Schuman, E. M. (2019). Spatially Stable Mitochondrial Compartments Fuel Local Translation during Plasticity. Cell 176, 73.e-84.e. doi: 10.1016/j.cell.2018.12.013

Rangaraju, V., Tom Dieck, S., and Schuman, E. M. (2017). Local translation in neuronal compartments: how local is local? EMBO Rep 18, 693-711. doi: 10. 15252/embr.201744045

Rihan, K., Antoine, E., Maurin, T., Bardoni, B., Bordonne, R., Soret, J., et al. (2017). A new cis-acting motif is required for the axonal SMN-dependent Anxa2 mRNA localization. RNA 23, 899-909. doi: 10.1261/rna.056788.116

Salcedo-Arellano, M. J., Cabal-Herrera, A. M., Punatar, R. H., Clark, C. J., Romney, C. A., and Hagerman, R. J. (2020). Overlapping Molecular Pathways Leading to Autism Spectrum Disorders, Fragile X Syndrome, and Targeted Treatments. Neurotherapeutics 18, 265-283. doi: 10.1007/s13311-020-00968-6

Savas, J. N., Ma, B., Deinhardt, K., Culver, B. P., Restituito, S., Wu, L., et al. (2010). A role for huntington disease protein in dendritic RNA granules. J Biol Chem 285, 13142-13153. doi: 10.1074/jbc.M110.114561

Savas, J. N., Makusky, A., Ottosen, S., Baillat, D., Then, F., Krainc, D., et al. (2008). Huntington's disease protein contributes to RNA-mediated gene silencing through association with Argonaute and P bodies. Proc Natl Acad Sci U S A 105, 10820-10825. doi: 10.1073/pnas.0800658105 
Scotter, E. L., Chen, H. J., and Shaw, C. E. (2015). TDP-43 Proteinopathy and ALS: Insights into Disease Mechanisms and Therapeutic Targets. Neurotherapeutics 12, 352-363. doi: 10.1007/s13311-015-0338-x

Selkoe, D. J. (2002). Alzheimer's disease is a synaptic failure. Science 298, 789-791. doi: 10.1126/science.1074069

Shirao, T., and Gonzalez-Billault, C. (2013). Actin filaments and microtubules in dendritic spines. J Neurochem 126, 155-164. doi: 10.1111/jnc.12313

Skup, M. (2008). Dendrites as separate compartment - local protein synthesis. Acta Neurobiol Exp (Wars) 68, 305-321.

Steward, O., and Fass, B. (1983). Polyribosomes associated with dendritic spines in the denervated dentate gyrus: evidence for local regulation of protein synthesis during reinnervation. Prog Brain Res 58, 131-136. doi: 10.1016/S0079-6123(08) 60013-8

Steward, O., and Levy, W. B. (1982). Preferential localization of polyribosomes under the base of dendritic spines in granule cells of the dentate gyrus. $J$ Neurosci 2, 284-291.

Steward, O., and Ribak, C. E. (1986). Polyribosomes associated with synaptic specializations on axon initial segments: localization of protein-synthetic machinery at inhibitory synapses. J Neurosci 6, 3079-3085.

Steward, O., Wallace, C. S., Lyford, G. L., and Worley, P. F. (1998). Synaptic activation causes the mRNA for the IEG Arc to localize selectively near activated postsynaptic sites on dendrites. Neuron 21, 741-751. doi: 10.1016/ s0896-6273(00)80591-7

Swanger, S. A., and Bassell, G. J. (2013). Dendritic protein synthesis in the normal and diseased brain. Neuroscience 232, 106-127. doi: 10.1016/j.neuroscience. 2012.12.003

Szostak, E., and Gebauer, F. (2013). Translational control by $3^{\prime}$-UTR-binding proteins. Brief Funct Genomics 12, 58-65. doi: 10.1093/bfgp/els056

Tashiro, K., Hasegawa, M., Ihara, Y., and Iwatsubo, T. (1997). Somatodendritic localization of phosphorylated tau in neonatal and adult rat cerebral cortex. Neuroreport 8, 2797-2801. doi: 10.1097/00001756-199708180-00029

Tiwari, S., Atluri, V., Kaushik, A., Yndart, A., and Nair, M. (2019). Alzheimer's disease: pathogenesis, diagnostics, and therapeutics. Int J Nanomedicine 14, 5541-5554. doi: 10.2147/IJN.S200490

Trancikova, A., Mamais, A., Webber, P. J., Stafa, K., Tsika, E., Glauser, L., et al. (2012). Phosphorylation of 4E-BP1 in the mammalian brain is not altered by LRRK2 expression or pathogenic mutations. PLoS One 7:e47784. doi: 10.1371/ journal.pone.0047784

Troca-Marin, J. A., Alves-Sampaio, A., and Montesinos, M. L. (2011). An increase in basal BDNF provokes hyperactivation of the Akt-mammalian target of rapamycin pathway and deregulation of local dendritic translation in a mouse model of Down's syndrome. J Neurosci 31, 9445-9455. doi: 10.1523/ JNEUROSCI.0011-11.2011

Tushev, G., Glock, C., Heumuller, M., Biever, A., Jovanovic, M., and Schuman, E. M. (2018). Alternative $3^{\prime}$ UTRs Modify the Localization, Regulatory Potential, Stability, and Plasticity of mRNAs in Neuronal Compartments. Neuron 98, 495.e-511.e. doi: 10.1016/j.neuron.2018.03.030

Walker, C. A., Randolph, L. K., Matute, C., Alberdi, E., Baleriola, J., and Hengst, U. (2018). Abeta1-42 triggers the generation of a retrograde signaling complex from sentinel mRNAs in axons. EMBO Rep 19, e45435. doi: 10.15252/embr. 201745435

Wang, B., Pan, L., Wei, M., Wang, Q., Liu, W. W., Wang, N., et al. (2015). FMRPMediated Axonal Delivery of miR-181d Regulates Axon Elongation by Locally Targeting Map1b and Calm1. Cell Rep 13, 2794-2807. doi: 10.1016/j.celrep. 2015.11.057

Wang, L. W., Berry-Kravis, E., and Hagerman, R. J. (2010). Fragile X: leading the way for targeted treatments in autism. Neurotherapeutics 7, 264-274. doi: 10.1016/j.nurt.2010.05.005

Wu, K. Y., Hengst, U., Cox, L. J., Macosko, E. Z., Jeromin, A., Urquhart, E. R., et al. (2005). Local translation of RhoA regulates growth cone collapse. Nature 436, 1020-1024. doi: 10.1038/nature03885

Yoon, B. C., Jung, H., Dwivedy, A., O’Hare, C. M., Zivraj, K. H., and Holt, C. E. (2012). Local translation of extranuclear lamin B promotes axon maintenance. Cell 148, 752-764. doi: 10.1016/j.cell.2011.11.064

Zhang, X., and Poo, M. M. (2002). Localized synaptic potentiation by BDNF requires local protein synthesis in the developing axon. Neuron 36, 675-688. doi: 10.1016/s0896-6273(02)01023-1

Zheng, J. Q., Kelly, T. K., Chang, B., Ryazantsev, S., Rajasekaran, A. K., Martin, K. C., et al. (2001). A functional role for intra-axonal protein synthesis during axonal regeneration from adult sensory neurons. J Neurosci 21, 9291-9303.

Conflict of Interest: The authors declare that the research was conducted in the absence of any commercial or financial relationships that could be construed as a potential conflict of interest.

Copyright (c) 2021 Gamarra, de la Cruz, Blanco-Urrejola and Baleriola. This is an open-access article distributed under the terms of the Creative Commons Attribution License (CC BY). The use, distribution or reproduction in other forums is permitted, provided the original author(s) and the copyright owner(s) are credited and that the original publication in this journal is cited, in accordance with accepted academic practice. No use, distribution or reproduction is permitted which does not comply with these terms. 